University of Nebraska - Lincoln

DigitalCommons@University of Nebraska - Lincoln

Faculty Publications, Department of Child, Youth, and Family Studies

Child, Youth, and Family Studies, Department of

7-1-2006

\title{
Mother-Child Bookreading in Low-Income Families: Correlates and Outcomes During the First Three Years of Life
}

\author{
Helen Raikes \\ University of Nebraska-Lincoln, hraikes2@unl.edu \\ Barbara Alexander Pan \\ Harvard Graduate School of Education \\ Gayle Luze \\ lowa State University \\ Catherine S. Tamis-LeMonda \\ New York University \\ Jeanne Brooks-Gunn \\ Columbia University, brooks-gunn@columbia.edu \\ See next page for additional authors
}

Follow this and additional works at: https://digitalcommons.unl.edu/famconfacpub

Part of the Family, Life Course, and Society Commons

Raikes, Helen; Pan, Barbara Alexander; Luze, Gayle; Tamis-LeMonda, Catherine S.; Brooks-Gunn, Jeanne; Constantine, Jill; Tarullo, Louisa Banks; Raikes, H. Abigail; and Rodriguez, Eileen T., "Mother-Child Bookreading in Low-Income Families: Correlates and Outcomes During the First Three Years of Life" (2006). Faculty Publications, Department of Child, Youth, and Family Studies. 39.

https://digitalcommons.unl.edu/famconfacpub/39

This Article is brought to you for free and open access by the Child, Youth, and Family Studies, Department of at DigitalCommons@University of Nebraska - Lincoln. It has been accepted for inclusion in Faculty Publications, Department of Child, Youth, and Family Studies by an authorized administrator of DigitalCommons@University of Nebraska - Lincoln. 


\section{Authors}

Helen Raikes, Barbara Alexander Pan, Gayle Luze, Catherine S. Tamis-LeMonda, Jeanne Brooks-Gunn, Jill Constantine, Louisa Banks Tarullo, H. Abigail Raikes, and Eileen T. Rodriguez 
Published in Child Development 77:4 (July/August 2006), pp. 924-953. doi:10.1111/j.1467-8624.2006.00911.x

Copyright (C) 2006 Society for Research in Child Development. Used by permission.

"This article may not exactly replicate the final version published in the SRCD journal. It is not the copy of record."

Mother-Child Bookreading in

\title{
Low-Income Families: Correlates and
}

\section{Outcomes During the First Three Years of Life}

\author{
Helen Raikes, University of Nebraska-Lincoln \\ Barbara Alexander Pan, Harvard Graduate School of Education \\ Gayle Luze, Iowa State University \\ Catherine S. Tamis-LeMonda, New York University \\ Jeanne Brooks-Gunn, Columbia University \\ Jill Constantine, Mathematica Policy Research Inc. \\ Louisa Banks Tarullo, Mathematica Policy Research Inc. \\ H. Abigail Raikes, University of Nebraska-Lincoln \\ Eileen T. Rodriguez, New York University
}

\begin{abstract}
About half of 2,581 low-income mothers reported reading daily to their children. At 14 months, the odds of reading daily increased by the child being firstborn or female. At 24 and 36 months, these odds increased by maternal verbal ability or education and by the child being firstborn or of Early Head Start status. White mothers read more than did Hispanic or African American mothers. For English-speaking children, concurrent reading was associated with vocabulary and comprehension at 14 months, and with vocabulary and cognitive development at 24 months. A pattern of daily reading over the 3 data points for English-speaking children and daily reading at any 1 data point for Spanish-speaking children predicted children's language and cognition at 36 months. Path analyses suggest reciprocal and snowballing relations between maternal bookreading and children's vocabulary.
\end{abstract}

Parental bookreading to children during the preschool years is normative behavior in many North American households (Bradley, Corwyn, McAdoo, \& Coll, 2001; National Cen- ter for Education Statistics [NCES], 1999) and is reliably linked to language and school readiness child outcomes (Bus, van Ijzendoorn, \& Pellegrini, 1995; DeBaryshe, 1993; 
Ninio, 1983; Sénéchal \& Cornell, 1993; Sénéchal, LeFevre, Hudson, \& Lawson, 1996; Snow \& Goldfield, 1983), although many of the findings are associative. Bookreading and literacy-related activities are especially advocated for low-income children at risk for academic and reading failure because these activities provide children with focused language experiences that tend to be similar in quality to those routinely experienced by children from more advantaged homes (De Temple \& Snow, 2003; Snow, 1998; Snow, Burns, \& Griffin, 1998, Snow et al., 1976; Whitehurst et al., 1994). However, there is a surprising lack of research on the importance of reading to children before age 3, and almost none pertaining specifically to low-income infants and toddlers, despite well-documented delays in language and cognitive development among these children by that age (Administration for Children and Families [ACF], 2003; National Institute of Child Health and $\mathrm{Hu}-$ man Development [NICHD], 2001). This study documents bookreading frequency and variation in a relatively large sample of low-income mothers and children in the context of the Early Head Start infant toddler intervention program and indicates critical links between maternal bookreading and children's language and cognitive development at 14 , 24 , and 36 months. We propose a theoretically based reciprocity model to elucidate the timing and pathways through which early literacy experiences may affect language development in this population, and to inform the design of language environments for low-income toddlers.

\section{Frequency of Parent-Child Bookreading}

In many North American households, older preschool-age children and their parents engage in regular bookreading. For example, $81 \%$ of parents in a nationally representative sample reported reading weekly to children 3-5 years of age (NCES, 1999), and 55\% of mothers surveyed in five biennial samples of the National Longitudinal Survey of Youth from 1986 through 1994 reported reading at least three times per week (Bradley et al., 2001). Although less frequent reading generally has been reported in low-income families (Anderson, Teale, \& Estrada, 1980; Whitehurst et al., 1994), wide variation in literacy-related activities has been documented in these households (Snow, 1987; Taylor \& Dorsey-Gaines, 1988). Moreover, the gap in parent-preschooler reading frequency between more affluent and less affluent parents may be widening (NCES, 1993, 1999), although analyses of Head Start samples show otherwise (ACF, 2003). Studies describing normative rates of parental reading to infants and toddlers are more limited. Approximately $45 \%$ of parents of toddlers in a representative U.S. sample reported reading daily (Britto, Fuligni, \& Brooks-Gunn, 2002), and 51\% read several times per week (Bradley et al., 2001). Parents of infants and toddlers who were not poor were twice as likely as poor parents to read several times per week (Bradley et al., 2001).

Variation in Bookreading and Children's Books in the Home

Many maternal characteristics relate to reading frequency. Across poor and nonpoor samples, Hispanic and African American mothers are less likely to read to their children than are White, non-Hispanic mothers (ACF, 2002a; Bradley et al., 2001; Britto et al., 2002; NCES, 1999; Yarosz \& Barnett, 2001). Non-English-speaking mothers read far less than mothers whose home language is English (NCES, 1999). Yarosz and Barnett (2001) found that only $48 \%$ of mothers whose home language was not English read to 3- to 5-year-old children during the preceding week, compared with $84 \%$ of mothers whose home language was English. Not surprisingly, maternal education (Lyytinen, Laasko, \& Poikkeus, 1998; Scarborough \& Dobrich, 1994) and maternal beliefs about the importance of literacy experiences for children (DeBaryshe, 1995) have been associated with more frequent bookreading. While demographic factors such as education level have been found to be associated with bookreading, no studies, until this one, have examined associations between cumulative demographic risk factors and maternal bookreading.

Fewer studies have acknowledged the contribution of child factors to the frequency of bookreading, although we do know that families spend more time in literacy-related activities with girls than with boys (Teale, 1986). We are not aware of studies relating bookreading to birth order, although mothers differ somewhat in the language they direct toward their firstborn and their later-born children (HoffGinsberg, 1998; Jones \& Adamson, 1987). Therefore, it is worth investigating whether early bookreading varies with child gender or birth order.

Developmental factors may be strongly related to bookreading frequency (Deckner, 2002), perhaps as a result of children's developing language (Scarborough \& Dobrich, 1994). In a Finnish study, 14-month-olds with larger vocabularies attended to books for longer periods of time, made more requests for reading, and engaged in longer periods of shared reading than did linguistically less 
advanced 14-month-olds (Lyytinen et al., 1998). Others have reported less interest in shared bookreading among children with language delays (Kaderavek \& Sulzby, 1998; Scarborough, Dobrich, \& Hager, 1991). However, even though bookreading to very young children is influenced by children's verbal competency, infants depend on adults to make books available and engaging (Lonigan, 1994). Thus, we examine both maternal variables and child variables as predictors of maternal bookreading.

\section{Availability of Children's Books}

This study also investigates the availability of children's books. Shared bookreading presumably is facilitated by easy access to children's books, which varies across and within groups. In families receiving public assistance, $48 \%$ reported having no alphabet books for their preschoolers, whereas only $3 \%$ of professional parents reported no books of this type (McCormick \& Mason, 1986). In a study of African American mothers and their 3- to 5-year-old children, mothers reported owning an average of 15 children's books, but the number varied widely across families (De Temple, 1999). Teale (1986) also reported wide variability within a low-income sample. Moreover, although many families can and do obtain children's books from public libraries, access to libraries is constrained by residential patterns and economic factors (Neuman \& Celano, 2001). Approximately $40 \%$ of parents with household incomes above the poverty threshold reported visiting a library at least once during the study period, compared with $24 \%$ of parents with household incomes below the poverty threshold (NCES, 1999). Families in geographically isolated rural areas, in dangerous urban areas, or without dependable, affordable means of transportation have more limited access to public library collections than do their counterparts. For those residing in the United States whose home language is not English, neither public libraries nor bookstores are likely to offer more than a few children's titles in the home language. One goal of the current study is to investigate the availability of children's books in a much larger sample than assessed elsewhere (e.g., De Temple, 1999; Teale, 1986) and to extend the examination to low-income families with children younger than 3 years of age.

\section{Bookreading and Children's Language and Cognitive Development}

Shared bookreading, typically measured by parent report in correlational studies, has been shown to be associated with the development of many skills during the toddler and preschool years. These skills include vocabulary development (Bus et al., 1995; DeBaryshe, 1993; Ninio, 1983; Sénéchal \& Cornell, 1993; Sénéchal et al., 1996; Snow \& Goldfield, 1983), book handling (Snow \& Ninio, 1986), knowledge about print (Clay, 1979), an understanding of fictional worlds represented symbolically in pictures and text (Snow \& Ninio, 1986), exposure to story structures and conventions necessary for story comprehension (Cochran-Smith, 1984), and positive attitudes about bookreading (Lonigan, 1994; Taylor \& Strickland, 1986). In a meta-analysis of 29 studies, preschool exposure to bookreading and print accounted for about $8 \%$ of the variation in children's language outcomes, with results consistent across social classes (Bus et al., 1995). In a longitudinal study conducted in Finland, shared bookreading was associated with vocabulary comprehension and symbolic gestures at 14 months, as well as with vocabulary production, sentence length, and cognitive skills as measured by the Bayley Mental Scales of Infant Development (Bayley, 1993) at 24 months (Lyytinen et al., 1998).

To our knowledge, no comparable longitudinal study of infants and toddlers has been conducted in the United States, particularly among low-income infants and toddlers. The lack of studies is problematic, given the early onset of language delays reported among children from low-income families (NICHD, 2001) and the acknowledged benefits of intensive language and preliteracy experiences for addressing delays among older preschool-aged children from low-income families (Snow, 1998; Whitehurst et al., 1994). In addition, no comparable study has been conducted of Spanish-speaking infants and toddlers, an important subgroup of low-income children (Yarosz \& Barnett, 2001). It is possible that (compared with English-speaking children) bookreading relates less powerfully to language outcomes among Spanish-speaking children, whose language learning might be conveyed in other culturally acceptable ways (e.g., through storytelling). In this study, we capitalize on the Early Head Start Research and Evaluation study sample that includes low-income English- and Spanish-speaking mothers and children.

\section{Intensity, Timing, and Patterns of Early Bookreading} During the Infant and Toddler Years

Although bookreading has been linked to children's outcomes, less is known about intensity and timing of bookreading experiences and early development. A na- 
tional study of preschool-aged children participating in Head Start (ACF, 2003) demonstrated that, compared with parents who read less frequently, more frequent reading in the fall was associated with both higher concurrent scores on literacy measures and larger gains during the year, even after controlling for parental education level, parental literacy level, and the presence of books in the home. Children of parents who reported reading to them "not at all" or "only once or twice a week" had receptive vocabulary scores that were lower than those of children whose parents reported reading "three to six times a week." Reading three to six times per week was associated with greater fall-to-spring vocabulary gains than was reading less frequently, and children whose parents reported reading daily had even larger gains. In addition, some research suggests that earlier regular experience with bookreading, beginning as young as 14 months, is particularly beneficial (e.g., DeBaryshe, 1995; Scarborough et al., 1991).

\section{Role of Transactions}

Although it is not bookreading frequency per se, but rather what actually happens during the interaction, that is likely to facilitate children's development, we have focused on the availability of the bookreading context for very young children from low-income families. Clearly, whatever benefits are to be gained from high-quality parent-toddler interaction around books can be realized only if children have access to that interaction more than just occasionally. Our concept of how bookreading may influence language and cognitive development is informed by a transactional model (Sameroff \& Fiese, 2000) in which child and environmental inputs affect one another reciprocally (Lewis \& Rosenblum, 1974; Sanson \& Rothbart, 1995). A transactional model has been proposed in the past to explain the effects of parent-child bookreading (Lyytinen et al., 1998; Scarborough \& Dobrich, 1994), and may help explain why some researchers have found the strongest effects for children with early reading experiences (DeBaryshe, 1995; Scarborough et al., 1991). In the current study, we ask whether early transactional influences begin a pattern or cycle that relates to outcomes at later ages.

\section{Covariates}

We also consider (as controls) other maternal and child variables suggested to be associated with variability in children's early language and cognitive development, including maternal level of education (Arriaga, Fenson, Cro- nan, \& Pethick, 1998; Bornstein, Haynes, \& Painter, 1998; Hoff, 2003) and maternal verbal skills and verbal interactions with their children (Bornstein et al., 1998; Hoff, 2003; Pan, Rowe, Singer, \& Snow, 2005). Some studies have shown higher levels of language ability among White children compared with those of other racial/ethnic backgrounds in the United States (Tabors, Roach, \& Snow, 2001). Other characteristics also play a role in early language and cognitive development. For example, according to some reports, during the early stages of vocabulary development, girls have slightly larger vocabularies than do boys (Bornstein et al., 1998; Fenson et al., 1994). Likewise, firstborn children tend to have slightly larger vocabularies than do later-born children, at least during the early years (Goldfield \& Reznick, 1990; Hoff-Ginsberg, 1998). Earlier levels of child verbal ability are also controlled in lagged models.

\section{Role of Intervention}

Finally, intervention programs, such as Early Head Start, may affect the literacy experiences parents provide children, as well as early language development in children (ACF, 2002b; Administration on Children, Youth and Families [ACYF], 2001; Brooks-Gunn, Klebanov, Liaw, \& Spiker, 1993; Ramey \& Campbell, 1991). The current study uses a purposely selected sample from 17 sites recruited to evaluate the Early Head Start intervention, a two-generation, federal program now serving approximately 62,000 very low income infants and toddlers in over 7,000 communities nationwide. Early Head Start aims to enhance children's development, and to foster positive parenting and self-sufficiency. However, it is not specifically a bookreading intervention (such as Even Start) and does not universally promote specific reading approaches (such as dialogic reading; Whitehurst et al., 1994). Child development services are delivered during weekly home visits (in home-based programs), through center-based services (in center-based programs), or a combination (in mixed-approach programs). As has been reported previously, Early Head Start parents in this sample read more frequently to their children than control group parents, and children had better language and cognitive development at 24 and 36 months of age (ACF, 2002b; ACYF, 2001; Love et al., 2005). The current study examines several factors, combined with Early Head Start, that may influence maternal reading and its relation to child outcomes. 
To summarize, this study assesses the timing, intensity, and patterns of maternal bookreading over time in a relatively large sample, and assesses the unique associations of bookreading with children's language and cognitive development after controlling for many covariates (race/ethnicity; maternal education; maternal verbal ability; maternal demographic cumulative risk; maternal warmth; child gender and child birth order; and, in 24 and 36 month analyses, earlier child verbal ability). This work is informed by a transactional model in which the child and the environment influence one another over time (Sameroff \& Fiese, 2000). Finally, we study bookreading in relation to the Early Head Start intervention. Specifically, we ask the following questions:

1. How many mothers of low-income children report engaging in joint bookreading, and does this percentage change during the child's first 3 years of life? How many children's books do children in these families have access to during the first 3 years of life? More mothers were expected to be reading with 24- and 36-month-old children than with 14-month-old children (see Britto et al., 2002). The frequency of shared bookreading in this low-income sample was expected to be either somewhat lower than in the general population of parents of infants and toddlers (Bradley et al., 2001) or, if our study findings are consistent with those of Head Start studies of bookreading (ACF, 2003), similar to bookreading among middle-income parents.

2. What are the characteristics of low-income mothers who engage in joint bookreading when children are 14, 24, and 36 months old? How does the availability of children's books vary according to characteristics of the mothers? On the basis of prior studies (Bradley et al., 2001; NCES, 1999), White mothers were expected to read more than African American mothers, who in turn were expected to read more than Hispanic mothers. Spanish-speaking Hispanic mothers were expected to read the least because they are relatively new to mainstream U.S. traditions with respect to language and preliteracy and might not have access to children's books in Spanish. Consistent with the literature, mothers of firstborn children and mothers of girls were expected to read more than other mothers, but these differences were expected to diminish as children grew older. Mothers with greater verbal ability and/or those with more education were expected to read more than their counterparts. Findings on the availability of books were expected to parallel those on reading frequency.

3. Does bookreading relate concurrently and cumulatively to children's language and cognitive development within English- and Spanish-speaking subsamples? Consistent with findings of studies of low-income 3- to 5-yearolds (ACF, 2002a; Bus et al., 1995; DeBaryshe, 1993), frequent bookreading (reading daily or several times weekly) was expected to be associated with children's language and cognitive development at every age, although effects might be strongest at 14 or 24 months in an English-speaking sample (DeBaryshe, 1995; Scarborough et al., 1991). Effects were expected to increase with intensity, with a pattern of consistent reading over time predicting outcomes at 36 months, controlling for many other factors known to be associated with bookreading and children's development. Given the limited studies on bookreading and outcomes for lowincome infants and toddlers in Spanish-speaking households in the United States, analyses for this subgroup were exploratory.

4.What are the reciprocal effects of maternal bookreading and child verbal ability over time? We provide a heuristic path model to explore the reciprocity of the influence of child vocabulary and bookreading over time, in accord with transactional models emphasizing the bidirectionality of child and environmental influences (Lewis \& Rosenblum, 1974; Sameroff \& Fiese, 2000; Sanson \& Rothbart, 1995). Early maternal reading and early child language were conceptualized to set in motion a pattern of reciprocal influences that may "snowball" to affect later child language and cognitive development.

5. What is the role of Early Head Start in maternal bookreading? How does Early Head Start, combined with maternal bookreading, relate to children's language and cognitive development? Consistent with previously reported impacts (ACF, 2002b; Love et al., 2005), Early Head Start was expected to predict daily bookreading, but only after 14 months, given that many children enrolled in the program late in the 1st year of life. Both Early Head Start and bookreading were expected to associate independently to children's development. These relations were expected for English-speaking children and possibly for Spanish-speaking children. 


\section{Method}

The data for this study are from the Early Head Start Research and Evaluation Project, an experimental design study conducted in 17 diverse programs (ACF, 2002b) from among the first two waves of Early Head Start programs funded. From 1996 through 1999, 3,001 children and families at or below the poverty level were recruited by Early Head Start programs according to the programs' normal procedures and randomly assigned into program and control groups. Random assignment resulted in demographically comparable groups (ACF, 2002b). Families could enroll while a mother was pregnant or any time before the child's first birthday. Demographic information was collected at program enrollment and was updated at each assessment. Assessments were completed when children were 14, 24, and 36 months old.

\section{Participants}

Participants in this study were the 2,581 mother applicants who answered questions during at least one of three interviews about their bookreading with their children. Table 1 reports characteristics of the sample at baseline. Many (39\%) of the mothers in the study were teens when the target child was born; 53\% had at least a General Education Development (GED) diploma or high school degree at the time of the study's onset, and $26 \%$ were married and living with a husband. About two thirds $(62 \%)$ of the children were firstborn, and $51 \%$ were male; $51 \%$ of the families were in the Early Head Start program. In addition, $37 \%$ of the mothers were White, 34\% were African American, 17\% were non-Englishspeaking Hispanic, 6\% were English-speaking Hispanic, and $4 \%$ were members of other racial or ethnic groups. Regression analyses across the three ages are based on the subset of 1,101 mothers $^{1}$ who completed all interviews at 14,24 , and 36 months and whose children completed 14-month assessments. Table 1 compares characteristics of mothers in the regression sample (e.g., 1,101 mothers with complete data) with other mothers in the full study sample (1,480 mothers). Footnote 1 further describes English- and Spanish-speaking subgroups within the regression sample. The regression sample included a larger proportion of mothers who were married and living with their husbands, more mothers with at least a GED or high school degree, and more White mothers. Despite small differences between the two samples, however, there was substantial representation of all major subgroups in the regression sample.
Measures

Demographic variables. Demographic data were obtained at baseline and during follow-up interviews. In a few cases, mothers who missed certain questions at baseline supplied the information later. Table 1 presents descriptive statistics, by demographic subgroups, for categorical variables used in the overall sample (Column 1) and the regression sample (Column 4). Demographic variables were included in analyses predicting bookreading patterns and as control variables in regression analyses that examined relations between bookreading and children's language and cognitive outcomes.

Mothers identified their race or ethnicity by selecting from U.S. Census categories for race and Hispanic origin. For the multivariate analyses, we created five categories combining race/ethnicity and language: (a) African American, (b) White, (c) Hispanic, English-speaking, (d) Hispanic, Spanish-speaking, and (e) other. We distinguished between English- and Spanish-speaking Hispanic mothers so as to better interpret language development outcomes (Garcia-Coll, 1995; Yarosz \& Barnett, 2001). In analyses that required dummy coding of racial groups, White mothers were coded as the referent group. A few respondents without data on race and Hispanic respondents without data on language were coded as missing. As analyses pertaining to child outcomes were conducted separately for Englishand Spanish-speaking groups, for the English-speaking group, new dummy codes were formed as described above excluding Spanish-speaking Hispanics and using White as the omitted referent group.

Questions about the highest level of education and years of education were asked at baseline and updated at the time of the birthday interviews. If baseline or updated education information was unavailable, the most recent reported year of education was used. The categorical education variable in Table 1 was used for the simulated means analysis, but the continuous education variable was used in regression analyses. Education data were missing for three respondents (at 14 months), and the sample mean value was substituted. In the regression sample, the average numbers of years of education for English- and Spanish-speaking groups were $11.84(S D=2.08)$ and $8.36(S D=3.79)$ at 14 months, $11.05(S D=2.02)$ and $8.72(S D=3.54)$ at 24 months, and $12.09(S D=1.94)$ and $8.73(S D=3.70)$ at 36 months.

A cumulative demographic risk variable was computed by summing four dichotomous maternal risk factors measured at baseline: (a) unmarried, (b) not in school or em- 
Table1

Sample Charactoristics

\begin{tabular}{|c|c|c|c|c|c|c|}
\hline Characteratic & $\begin{array}{l}\text { Sendy } \\
\text { sample }\end{array}$ & $\begin{array}{l}\text { Not in } \\
\text { sample }\end{array}$ & $x^{2}$ & $\begin{array}{l}\text { Regresion } \\
\text { sample }\end{array}$ & $\begin{array}{l}\text { In study sample not } \\
\text { regresion sampled }\end{array}$ & $x^{2}$ \\
\hline$N$ & $2,495-2,500$ & $389-420$ & & $1,078-1,01$ & $1,434-1,450$ & \\
\hline Education & 2,49 & $\mathbf{3 1}$ & $11.52^{* *}$ & 1,060 & 1,434 & $684^{*}$ \\
\hline Les than HS/GFD (5) & 46.6 & 54.5 & & 438 & 486 & \\
\hline $\mathrm{HS} / \mathrm{CFD}(\mathrm{s})$ & 28.8 & 27.9 & & 293 & 284 & \\
\hline More than (S)HS/CFD & 24.6 & 17.6 & & 269 & 230 & \\
\hline Age of mothert" & 2,518 & 35 & $0.21(s)$ & 1,098 & 1,40 & $001(n)$ \\
\hline Teenaged (\$) & 39.0 & 4. 3 & & 390 & 391 & \\
\hline Not teeraged (5) & 61.0 & 397 & & 610 & 609 & \\
\hline Lves & $2,5 \pi 6$ & 413 & $22.58^{\cdots}$ & 1,098 & 1,48 & $9.76 \%$ \\
\hline Wah huskand (s) & 260 & 30.1 & & 288 & 239 & \\
\hline Whth others (s) & 39.6 & 33.4 & & $36 \mathrm{~J}$ & 417 & \\
\hline Aboe (3) & 34.5 & 4.5 & & 345 & 344 & \\
\hline Race/largaage' & 2,580 & 420 & $15.82^{* *}$ & $1,10 \pi$ & 1,400 & $17.53 \%$ \\
\hline Whete (5) & 36.6 & 35.2 & & 409 & 334 & \\
\hline African American (6) & 34.2 & 32.6 & & 324 & 35.5 & \\
\hline Hsparic/Sparish (\%) & 17.3 & 15.7 & & 153 & 187 & \\
\hline Hisparic/English (s) & 06.9 & 060 & & 06.1 & 064 & \\
\hline Othes (s) & 04.3 & 060 & & 045 & 041 & \\
\hline Massing (5) & 01.8 & 04.5 & & 018 & 018 & \\
\hline Cumulative demographbe ris k8 & 2,580 & 420 & $1210^{\circ}$ & $1,10 \pi$ & 1,450 & $1571 \%$ \\
\hline $0(\$)$ & 06.7 & 6.2 & & 064 & 06.2 & \\
\hline $1(3)$ & 28.4 & 22.6 & & $30 \mathrm{z}$ & 268 & \\
\hline $2(\$)$ & 38.2 & 3.4 & & 38.1 & 384 & \\
\hline $3(\%)$ & 23.6 & 3) 7 & & 222 & 247 & \\
\hline $4(\$)$ & 040 & 04.0 & & 026 & 060 & \\
\hline Status & 2,506 & 393 & $7.69^{\circ}$ & 1,065 & $1,4,5$ & $\$ 17$ \\
\hline Employed (5) & 24.1 & 18.3 & & 257 & 230 & \\
\hline In school (\%) & 21.9 & 21.1 & & 229 & 21.1 & \\
\hline Neithe (5) & 54.0 & a.6 & & 51.4 & 559 & \\
\hline AFDC/TANF & 2,580 & 420 & $8.52^{\circ}$ & 1,100 & 1,450 & $106(n)$ \\
\hline Yes (6) & 307 & 3.9 & & 296 & 31.5 & \\
\hline No (5) & 69.3 & 2.1 & & 704 & 685 & \\
\hline Birth order & 2,580 & 420 & $706^{\circ}$ & 1,100 & 1,450 & $046(n s)$ \\
\hline Firstoorn (\$) & 61.6 & 80.6 & & 624 & 611 & \\
\hline Lateg boen (6) & 38.4 & 31.4 & & 376 & 389 & \\
\hline Gender & 2,580 & 420 & $0.52(4)$ & 1,100 & 1,450 & $095(n)$ \\
\hline Male (\$) & 50.8 & 2.8 & & $49 z$ & 51.6 & \\
\hline Fembe (\$) & 49.2 & 4.2 & & 503 & 484 & \\
\hline Propram" & 2,500 & 420 & $1.15(\Leftrightarrow)$ & 1,001 & 1,450 & 181 \\
\hline EFS (\$) & 50.9 & 450 & & 524 & 497 & \\
\hline Control (5) & 49.1 & 20 & & 476 & 503 & \\
\hline
\end{tabular}

Note. All data were collected at baseline.

"Study sample" indudes mothers who answered questions about bookresding.

"Nok in study sample" inchides primary caregivers in the original EHS sample who did nok answer questions about bookresd ing and caregivers who were not mothers or appliants.

"'Regression sample" includes mothers who completad interviews when their children were 14, 24, and 36 months of age and who had child assessment data at 14 months.

d'Not in regression sample" includes mothers who answered questions about bookreading once and who did not meet criteris for the selexted semple.

"Age of mother" refers to the mother's age when the child was bom.

"The race categories inchude a treakdown of Hispanic primary caregivers into those who were English speaking and those who were Spanish spes ling.

"Cunn btive demographic risks" include the following: mother was tenaged, was not married, was not in school, and was receiving cash assistance.

"Program" refers to whether the dild was in the EHS program or the control group.

$* p \leq 05, * * \leq 01, * * p \leq 001$

AFDC = Aid to Families with Dependent Children; EHS = Early Hesd Start; GED = General Ed ucation Development diplama; HS = high school; TANF = Temponary Assistance for Needy Families. 
ployed, (c) teenagers at the time of the target child's birth, and (d) currently receiving welfare cash assistance. Cumulative risk has been a powerful predictor of parental and child outcomes in other studies (Liaw \& Brooks-Gunn, 1994; Sameroff \& Fiese, 2000). In the current study, preliminary analyses showed that cumulative risk was a better predictor of maternal bookreading and child outcomes than were individual variables. English-speaking mothers averaged 1.86 risks $(S D=0.94)$, whereas Spanish-speaking mothers averaged $1.74(S D=0.88)$.

Other demographic predictors included child gender and whether the child was firstborn. About half of the children in the sample were males (49.7\%), with $49.2 \%$ males in the English-speaking group and 52.1\% males in the Spanishspeaking group. Overall, a majority of children were firstborn (62.4\%), with $64.7 \%$ of English-speaking children being firstborn and $49.7 \%$ of Spanish-speaking children being firstborn. Finally, families' program status was determined by random assignment at baseline. About half of the families were in the program $(52.4 \% ; 51.6 \%$ of the Englishspeaking group and $56.8 \%$ of the Spanish-speaking group).

Mother verbal ability and warmth. The WoodcockJohnson Psychoeducational Battery-Revised, Picture Vocabulary Test (WJ), a measure of maternal expressive verbal ability requiring the mother to provide verbal labels for a set of pictures (Woodcock \& Johnson, 1990), was administered to mothers when their children were 24 months of age. Standard scores were computed using the WoodcockMuñoz Language Survey Normative Update (Woodcock \& Muñoz-Sandoval, 2001a, 2001b). Mothers assessed in Spanish completed the Spanish form and mothers assessed in English completed the English form. For both groups, the appropriate language group norms were used to compute standard scores. Data were missing for 158 mothers. Therefore, to maintain sample size and not considering attrition to be random, we regressed observed $\mathrm{WJ}$ scores on baseline demographics, using ordinary least squares (OLS) regression to impute missing scores on the $\mathrm{WJ}^{2}$ The observed sample mean was 89.69 , and the standard deviation was 11.76 (imputed sample mean $=89.77 ; S D=11.14$ ). Standardized scores ranged from 56 to 130 . Outcomes with and without imputed values were similar. When reporting descriptive data and for the simulated means analyses, we divided the sample into two groups ( $\leq 85$ and $>85$ on the $\mathrm{WJ}$; population mean $=100$ ). Approximately $29 \%$ of the sample scored at or below 85. Regression sample English-speaking mothers averaged $91.67(S D=10.46)$ and Spanish-speaking mothers averaged $79.26(S D=8.64)$.

We considered it important to control for mother-child interaction more generally when estimating the possible effect of mother-child bookreading on child cognitive and language outcomes. Thus, at each of the three ages, a measure of maternal warmth served as a control, based on the Home Observation for Measurement of the Environment (HOME; Caldwell \& Bradley, 1984). The variable measured responsive and supportive parenting as observed during the home visit and included such items as whether the mother praised the child, expressed warmth and affection toward the child, and responded verbally to the child during the visit. Items were identical at 14 and at 24 months and were similar but slightly different at 36 months (Fuligni, Han, \& Brooks-Gunn, 2004). Cronbach coefficient $\alpha$ s for the three scales at each of the three ages were $.74, .74$, and .72. Missing values ( $n=29$ at 14 months, $n=61$ at 24 months, and $n=123$ at 36 months) were imputed in the same manner as for the WJ scores. ${ }^{3}$ Regression sample English-speaking mothers were rated slightly lower in maternal warmth than Spanish-speaking mothers at 14, 24, and 36 months: 6.07, $S D=1.38 ; 6.17, S D=1.30$; and $2.55, S D=0.78$ for Englishspeaking mothers versus 6.32, $S D=0.99 ; 6.44, S D=0.97$; and 2.75, $S D=0.57$ for the Spanish-speaking mothers.

Bookreading frequency and children's access to books. At each of the three ages, mothers were asked, "Please let us know how many times in the past month you read [stories] with your child: more than once a day, about once a day, a few times a week, a few times a month, rarely, not at all." Responses of more than once a day and about once a day were recoded as daily, and responses of rarely and not at all were recoded as rarely, resulting in four values for the bookreading variable: daily $=3$, a few times a week $=2$, a few times a month $=1$, and rarely $=0$ to reduce the number of outcome variables for ordinal scale analyses. Self-report of frequency of bookreading was considered a more appropriate measure than asking parents to identify book titles (vs. foils) from a list of children's books, a reliable predictor of literacy activities for preschool-age children (Sénéchal \& LeFevre, 2002; Sénéchal, LeFevre, Thomas, \& Daley, 1998), given similarities among titles of infant/toddler picture books.

Mothers were also asked about children's books in the home. At 14 and 24 months, they were asked, "About how many books do you have for your [child]?" The response categories ranged from 0 to 5 or more. At 36 months, the 
mothers were asked, “How many children's books does your child have of his/her own?" The response categories ranged from 1 or 2 to 10 or more.

Child language and cognitive measures. The mothers were asked to complete the MacArthur Communicative Development Inventories (CDI) Short Form (Fenson et al., 2000) when their children were 14 and 24 months old. The Infant Form, administered when children were 14 months old, consists of a checklist of 89 words from which parents identified words they judged their children to comprehend or produce; this form yielded measures of vocabulary comprehension and production. At 24 months, parents were asked to complete the Toddler Form, on which they indicated the words from a list of 100 that the children produced; this form yielded a measure of vocabulary production. To ensure the validity of maternal reports of child language, separate analyses were conducted from a sample of 105 families at two of the study sites that had collected observed language data. These analyses showed that overall associations between raw scores on the CDI and observed child language at 14 and 24 months were moderate to strong and predicted receptive language measured 1 year later with the Peabody Picture Vocabulary Test, Third Edition (PPVT-III) better than did observed language production (Pan, Rowe, Spier, $\&$ Tamis-LeMonda, 2004). Thus, we retained the CDI measures in the analyses reported here.

When the children were 36 months old, the mothers were asked whether the child's stronger language was English or Spanish. ${ }^{4}$ We administered the PPVT-III (Dunn \& Dunn, 1997), a widely used measure of receptive vocabulary. TVIP, a Spanish adaptation of the PPVT-III (Dunn, Padilla, Lugo, \& Dunn, 1986), was administered to Spanish-speaking children. In both tests, the child is shown four pictures and is asked to match a word that the interviewer says out loud to the corresponding picture. The PPVT-III has good internal consistency reliability (Cronbach's $\alpha=.92-.98$ ) and correlates highly (.8-.9) with intelligence tests. The authors' report split half reliabilities of .91 for children aged 3 years and of .80 for children aged $2 \frac{1}{2}-3$ years. Cronbach $\alpha$ s for the PPVT-III and TVIP in a sample of low-income children were .97 and .92, respectively (ACF, 2003).

Standardized scores from the MDI (Bayley, 1993) at 14, 24 , and 36 months were cognitive measures. In the norming sample, MDI internal reliability was .88, test-retest reliability ranged from .77 to .91 , and the MDI was correlated with other tests of cognitive functioning, including the Mc-
Carthy Scales of Children's Abilities (.79) and the Wechsler Preschool and Primary Scale of Intelligence-Revised (.73). Although the Bayley MDI provides a score on children's general cognitive status, many items tap children's emerging receptive and productive language skills, with language items becoming increasingly prominent at the 24- and 36month assessments. For example, at 14 months, experimenters ask infants to point to named pictures (receptive language) or to name objects in pictures (productive language). At 24 months, assessments are made of children's ability to combine words and gestures, understand complex commands with descriptive words (e.g., color names), use of prepositions, oral counting, and repetition of sequences. By 36 months, items include assessments of whether children ask questions, produce multiword utterances, count, use prepositions, name colors, and so forth. Consequently, the Bayley MDI is associated with other observational measures of children's language, including children's word types and tokens in low-income Early Head Start populations (Pan et al., 2004).

\section{Results}

We first present descriptive findings on reported mother-child bookreading frequency at each age and chi-square analyses of differences in reported mother-child bookreading frequency and availability of children's books at each age among families with different characteristics (e.g., education levels). Second, we report results of logistic regression analyses in which significant background variables were examined for their relationships to reported reading at each age. To address the third research question - whether reported mother-child bookreading frequency relates to child language and cognitive outcomes at 14, 24, and 36 months - we present results of three sets of regression analyses: one using concurrent bookreading frequency as the key predictor, one examining timing and intensity of bookreading, and the third examining patterns of reading over time. Next, a regression path model was used to explore reciprocity between earlier reading and child abilities and later reading experiences and child language outcomes. Finally, regression-estimated simulated means model the separate and combined effects of bookreading, completing high school, and Early Head Start intervention.

Frequency and Determinants of Reading and Availability of Books

In the full study sample, approximately half (48.3\%) of the mothers reported reading daily to their children at 14 
months, $29.0 \%$ reported reading several times per week, $10.6 \%$ reported reading several times per month, and $12.2 \%$ reported rarely reading to their children (Figure 1). More mothers reported daily reading at 24 and 36 months (55.1\% and $54.4 \%$, respectively) than at 14 months. The number of mothers who read to their children several times per month or rarely decreased with children's age. ${ }^{5}$ Most of the children had access to children's books; at 14 months and 24 months, $80 \%$ and $85 \%$ of the children, respectively, had five or more children's books. At 36 months, $84 \%$ had 10 or more children's books (Figure 2).

Associations with child and maternal characteristics. Table A1 presents chi-square analyses of the full study sample showing associations between reported bookreading and mother characteristics (i.e., verbal ability, education, race/ethnicity/language, and level of demographic risk), child characteristics (i.e., gender and birth order), and Early Head Start participation. When children were 14 months of age, mothers reported reading more frequently to girls and firstborn children than to boys and children born later. Mothers with at least a high school education and with verbal abilities above 85 on the WJ scale (population mean $=100$ ) read books more frequently to their 14-monthold children than did their respective counterparts. White, African American, and English-speaking Hispanic mothers reported reading more frequently than did non-Englishspeaking Hispanic mothers. Results at 24 and 36 months were similar to those at 14 months, except that gender differences were not observed at 24 months. At 24 months, children in Early Head Start were read to more frequently than were children in the control group, not controlling for simultaneous associations with other variables.

The availability of children's books generally paralleled bookreading frequency (Table A2). In some cases, the differences in the availability of children's books were quite striking. For example, $90.7 \%$ of White, $90.6 \%$ of English-speaking Hispanic, and $77.6 \%$ of African

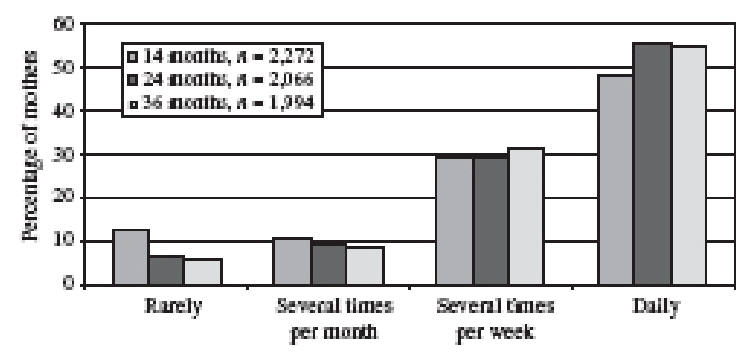

Figure 1. Percentage of mothers reporting bookresding at 14, 24, and 36 manths.

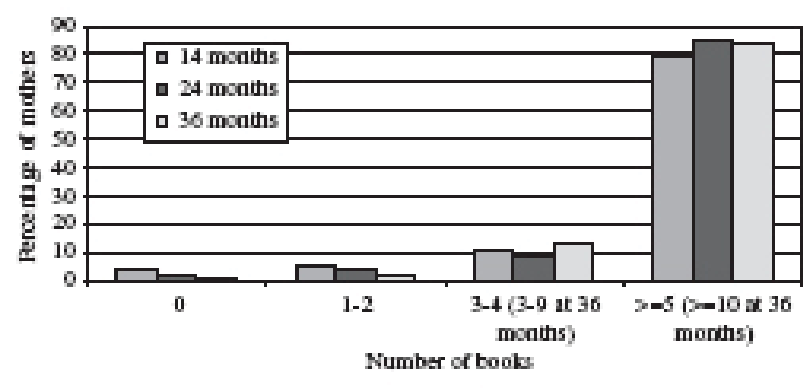

Figure 2. Percentage of mothers reporting a vailability of children's books at 14, 24, and 36 months.

American children had five or more children's books when they were 14 months old, whereas only $58.5 \%$ of Spanishspeaking Hispanic children had access to that number of books in their homes. This pattern continued at 24 and 36 months, although older children in all groups were more likely than younger children to have access to children's books.

Parent/child characteristics and daily/rarely reading: logistic regression analyses. We next conducted logistic regression analyses at all three ages, using the regression sample, to examine the influence of multiple variables on the likelihood of mothers reading to their children daily (vs. all other frequencies of reading); parallel analyses were undertaken for the likelihood of mothers reading rarely (see Table 2 for both sets of results). ${ }^{6}$ At 14 months, English- and Spanish-speaking Hispanic children were about half as likely as White children to be read to daily (odds ratios $=0.54$ and 0.60 , respectively), and boys were about two thirds as likely as girls to be read to daily (odds ratio $=0.67$ ). Being firstborn increased the odds for daily reading (1.36), as did every year of maternal education (1.08) (in all analyses, $p<.05$ ).

At 24 months, African American, English-speaking Hispanic, and Spanish-speaking Hispanic mothers were less likely than were White mothers to report reading to their children daily (odds ratios $=0.59,0.42$, and 0.61 , respectively). Maternal education level (1.11), verbal ability (1.02), and participation in the Early Head Start program (1.41) all increased the likelihood that mothers would read daily to their children; firstborn children still were more likely to be read to daily (1.45) than were later-born children.

At 36 months, maternal education (1.14), verbal ability (1.02), Early Head Start program participation (1.29), and being firstborn (1.50) continued to increase the chances that children would be read to daily, as reported by their mothers. African American children (0.66) and Spanish-speaking 
Table2

Legistis Regression Predisters of Daily Ronding and Ronding Rarcly at 14, 24, and 36 Mouths

\begin{tabular}{|c|c|c|c|c|c|c|}
\hline \multirow[b]{2}{*}{ Predictor } & \multicolumn{2}{|c|}{14 months } & \multicolumn{2}{|c|}{24 months } & \multicolumn{2}{|c|}{36 manths } \\
\hline & Doily & Rarely & Daily & Rarely & Daily & Ra rely \\
\hline \multicolumn{7}{|l|}{ (White, onnitted) } \\
\hline African American & $0.05(0.16) 1.05$ & $-.18(0.28) 0.83$ & $-0.54(0.17) 0.59 * * *$ & - $-23(0.44) 0.80$ & $-.42(0.17) 0.66^{\circ}$ & $0.43(0.43) 1.54$ \\
\hline Hispanic/Spanish & $-0.50(0.23) 0.60^{\circ}$ & $64(0.32) 1.89$ & $-0.49(0.23) 0.61^{*}$ & $.46(0.47) 1.39$ & $-44(0.23) 0.64$ & $0.72(0.51) 2.05$ \\
\hline $\mathrm{Hispanic/English}$ & $-0.61(0.30) 0.54^{*}$ & $23(0.46) 1.26$ & $-0.75(0.30) 0.42^{*}$ & $23(0.69) 1.25$ & $-33(0.30) 0.72$ & $1.03(0.60) 2.80$ \\
\hline Other & $-0.49(0.31) 0.61$ & $-.15(0.56) 0.86$ & $-0.33(0.32) 0.72$ & $54(0.68) 1.72$ & $-23(0.32) 0.80$ & $-0.30(1.07) 0.74$ \\
\hline Missing race & $-1.12(0.55) 0.33$ & $82(0.58) 2.27$ & $-2.12(0.67) 0.12^{* *}$ & $31(0.20) 1.37$ & $.42(0.52) 1.52$ & $0.58(0.90) 1.79$ \\
\hline Risk & $-0.03(0.0) 0.97$ & $-.08(0.11) 0.92$ & $0.02(0.07) 1.02$ & $-.20(0.16) 0.82$ & $-01(0 . \sigma) 0.99$ & $0.08(0.16) 1.09$ \\
\hline Matemal verbal ability & $0.01(0.01) 1.01$ & $-.03(0.01) 0.97^{* *}$ & $0.02(0.01) 1.02 * *$ & $-05(002) 0.95^{* *}$ & $\quad 02(0.01) 1.02^{* *}$ & $-0.05(0.02) 0.96 * *$ \\
\hline Matemal education & $0.05(0.03) 1.05$ & $-.09(0.04) 0.92$ & $-1.1(0.03) 1.11^{* *}$ & $-.15(005) 0.87^{* *}$ & $.13(0.03) 1.14^{* * *}$ & $-0.11(0.06) 0.90$ \\
\hline Finstbom & $0.31(0.13) 1.36^{\circ}$ & $-33(0.20) 0.72$ & $0.37(0.14) 1.45^{* *}$ & $-22(0.30) 0.45$ & $.41(0.14) 1.50^{* *}$ & $-0.34(0.30) 0.80$ \\
\hline Male & $-0.40(0.13) 0.67^{* * *}$ & $32(0.20) 1.38$ & $-0.17(0.13) 0.85$ & $34(0.28) 1.41$ & $-.11(0.13) 0.91$ & $0.68(029) 1.97^{*}$ \\
\hline EHS program & $-0.19(0.13) 0.83$ & $-38(0.20) 0.68$ & $0.34(0.13) 1.41^{* *}$ & $-66(0.29) 0.52^{*}$ & $26(0.13) 1.29^{*}$ & $-0.38(0.28) 0.69$ \\
\hline$N$ & 1,101 & 1,101 & 1,101 & 1,101 & 1,101 & 1,101 \\
\hline$x^{2}$ & 7269 & 7762 & 105.37 & 74.57 & 99.35 & 57.82 \\
\hline Cox and Sinell $R^{2}$ & 006 (11) & 07 (11) & 009 (11) & $\sigma(11)$ & 09 (11) & 005 (11) \\
\hline
\end{tabular}

Note. Logistic regression analyses compared mothers who resd daily with all others and mothers who resd narely with all others at 14,24 . and 36 months. Vahes are unstandardized $\beta$ coefficients, folkwed by the standard errors in parentheses and the exponentisl $\beta$ values. Modek included mother's race (African American, Hispanic Englishspesling, Hispanic Spanish-spesking, other race, and missing race, with White as the omitted referent group); mother's number of demographic risks (summod score of whether a teenaged parent, employed or in school, marriod, and receiving Aid to Families with Dependent Children at the time of nondom assignment); mother's Woodoock Johnson Picture Vocabulary scone; mother's highest kevel of education; whether the child was firstbom; whether the child was mak; and whether the child was in the EHS program. We ako computed resding several times per week versus all other kevels of resding, but results were similar to those for dasily residing and a re nok reportod here.

$* p \leq 05, * p \leq 01, \cdots p \leq 001$

EHS = Early Head Start.

Hispanic children ( 0.64 , a trend) were about two thirds as likely as White children to be read to daily at 36 months.

Consistency of reading over time. Next, we examined factors associated with patterns of children's exposure to reading during the infant and toddler years (Table $3)$. One fourth $(27 \%)$ of the mothers reported reading to their children daily at all three ages $(14,24$, and 36 months). African American and Spanish-speaking Hispanic mothers were less likely than White mothers to report doing so (odds ratios $=0.54$ and 0.39 , respectively). Each year of maternal education increased the chances that mothers would read daily to their children at all three ages (odds ratio=1.29); firstborn children were more than twice as likely to be read to daily at all ages than later-born children (odds ratio $=1.91$ ), and boys were less likely than girls to be read to daily at all ages (odds ratio $=0.71$ ). More than a quarter of the sample reported always reading to children several times a week (28\%), and a quarter reported reading several times a week during at least two of the time points (24\%), whereas the rest reported reading several times a week at only one or none of the assessment points (i.e., rarely reading, $21 \%$ ). Although Early Head Start programs did not increase the probability of daily reading at all three points, being in the program increased the odds of being read to several times a week at the three assessments (odds ratio=1.64).

\section{Bookreading and Children's Language and Cognitive Development}

Analyses of children's language and cognitive skills at the three ages in relation to bookreading were conducted separately for children of English- and Spanish-speaking mothers. The regression-sample English-speaking mothers reported that children at 14 months of age comprehended an average of 48.46 words $(S D=18.66$, range $3-89, n=932)$ and produced 12.12 words $(S D=11.01$, range $1-83, n=932$ ). At 24 months, children produced an average of 55.92 words $(S D=22.10$, range $0-100$, $n=906)$. Spanish-speaking mothers reported that their children at 14 months comprehended an average of 45.15 words $(S D=20.70$, range $=2-89, n=169)$ and produced 9.72 


\begin{tabular}{|c|c|c|c|c|c|c|c|c|c|}
\hline \multirow{3}{*}{$\frac{\text { Predictor }}{\text { (White, onitted) }}$} & \multicolumn{3}{|c|}{ Doily at three ages } & \multicolumn{3}{|c|}{$\begin{array}{l}\text { At lesst several times a } \\
\text { week at three ages }\end{array}$} & \multicolumn{3}{|c|}{$\begin{array}{l}\text { Several times a week at } \\
\text { two ages but not three }\end{array}$} \\
\hline & \multicolumn{3}{|c|}{$\begin{array}{c}n=300 \\
(272 \% \text { of smple) }\end{array}$} & \multicolumn{3}{|c|}{$\begin{array}{c}n=310 \\
(282 \% \text { of } \leqslant \text { smple) }\end{array}$} & \multicolumn{3}{|c|}{$\begin{array}{c}n=265 \\
(24.1 \% \text { of sample) }\end{array}$} \\
\hline & & & & & & & & & \\
\hline African American & -0.61 & $(026)$ & $0.54^{*}$ & -30 & (24) & 0.74 & -.02 & (24) & 0.98 \\
\hline $\mathrm{Hispanic/Spanish}$ & -0.95 & $(0.36)$ & $0.39^{* *}$ & $-\$ 99$ & (35) & $0.56^{*}$ & -32 & (33) & 0.77 \\
\hline 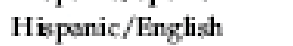 & -1.11 & $(0.44)$ & $0.33^{*}$ & -84 & $(42)$ & $0.43^{*}$ & -81 & (43) & $0.45^{\circ}$ \\
\hline Other & -0.81 & $(0.50)$ & 0.11 & -08 & (45) & 0.93 & -38 & (49) & 0.69 \\
\hline Missing race & -2.98 & (1.34) & $0.05^{*}$ & -.48 & $(73)$ & 0.62 & .18 & (39) & 1.19 \\
\hline Risk & -0.02 & (0.11) & 0.98 & .06 & (.11) & 1.06 & -.10 & (.11) & 0.91 \\
\hline Matemal verbal ability & 0.02 & $(0,1)$ & $102^{*}$ & 04 & (01) & $1.04^{* *}$ & 01 & (O1) & 101 \\
\hline Matemal education & 0.25 & $(006)$ & $1.29^{* * *}$ & .13 & (05) & $1.14^{*}$ & 02 & (04) & 102 \\
\hline Finstbom & 0.65 & $(022)$ & $1.91^{* *}$ & 60 & (21) & $1.83^{* *}$ & 01 & (.19) & 101 \\
\hline Make & -0.35 & $(0.20)$ & $0.71^{*}$ & -.47 & (19) & $0.63^{*}$ & -.11 & (.19) & 0.90 \\
\hline EHS program & 0.21 & $(0.20)$ & 1.27 & 50 & (.19) & $164^{* *}$ & 21 & (.19) & 1.24 \\
\hline$x^{2}$ & \multicolumn{3}{|c|}{119.74} & \multicolumn{3}{|c|}{859} & \multicolumn{3}{|c|}{1354} \\
\hline Cax and Snell $R^{2}$ & 0.20 & (11) & & .15 & (11) & & 04 & (11) & \\
\hline
\end{tabular}

Note. In three separate bogistic regression analyses, daily resding at three ages $(n-300)$, resding several times a week at three ages $(n-310)$, and resding several times a week at two ages $(n-265)$ were compared with reading a maximu m of several timks a week at cane age or less $(n-226)$. Bookresding was asessed at 14,24 , and 36 months. Values are unstandardived $\beta$ coefficients, followed by the standard errors in parentheses and the exponentisl B values. Modek inchuded mother's race (African American, Hispanic Englishspesking, Hisponic Spanish-speaking, other race, and missing race, with Whits as the onitted referent group); mother's number of demographic riks (summed sore of whether a teenaged parent, employed or in school, married, and receiving Aid to Families with Dependent Children at the time of random assignment; mother's Woodoock-kohnson Picture Vocabu bry score; mother's highest kevel of education; whether the child was firstborn; whether the dild was male; and whether the child was in the EHS program.

$* p \leq-05, * p \leq .01, * * p \leq 001$

EHS = Early Hesd Start.

words $(S D=10.71$, range $=1-57)$. At 24 months, their children produced a vocabulary of 51.16 words $(S D=25.22$, range $=0-100, n=161)$. At 36 months, 765 English-speaking children completed the PPVT-III and received an average score of $84.29(S D=15.28$, range $=40-123)$; 108 Spanishspeaking children completed the TVIP averaging a score of 94.73 ( $S D=7.20$; range 82-124). For English-speaking children, the average MDI score at 14 months was 98.91 $(S D=10.85$, range $=51-130, n=932)$ and for Spanish-speaking children, $97.94(S D=11.29$, range $=58-122, n=169)$; at 24 months, the average MDI score for English-speaking children was $90.34(S D=13.72$, range $=49-129, n=803)$ and for children in the Spanish-speaking sample, 85.30 $(S D=13.58$, range $=49-112, n=149)$. At 36 months, the average MDI score for English-speaking children was 91.83 $(S D=12.14$, range $=49-127, n=770)$. For Spanish-speaking children, the average 36-month MDI score was 90.17 $(S D=12.19$, range $=49-121, n=99)$.

Concurrent reading and language and cognitive skills. We used OLS regression to examine concurrent associations between mother-child bookreading and children's cognitive and language skills, controlling for maternal and child background characteristics and maternal warmth. We also included the child's 14-month vocabulary score to predict outcomes at 24 and 36 months. For each outcome, separate analyses were conducted using each of the following dichotomous reading variables: (a) daily versus all other frequencies, (b) several times per week or more versus all other frequencies, and (c) rarely versus all other frequencies. ${ }^{7}$ For the English-speaking mothers at 14 months, all three levels of concurrent reading were associated with child vocabulary and comprehension, but not MDI scores. At 24 months, even after controlling for 14month vocabulary, all three levels of concurrent reading were associated with child vocabulary, whereas reading daily and several times a week related to MDI scores. At 36 months, reading several times a week related to MDI scores. None of the concurrent reading variables were associated with PPVT-III scores. For Spanish-speaking mothers, there were inconsistent relations between reported reading and outcomes at 14 or 24 months (not shown). At 14 months only, reading several times a week was associated with comprehension $(S B=.18, p=.03)$, and at 24 months only, reading several times a week was marginally 
associated with child vocabulary $(S B=.16, p=.07)$, but the expected relations for daily reading appeared at 36 months (shown in Table 4).

Frequency and timing of bookreading and children's language and cognitive skills. Questions of how early the relations between mother-child joint bookreading and outcomes are observable and of how the intensity of bookreading associates with outcomes (e.g., daily or several times a week) are of theoretical and applied interest. Thus, for each age, reading variables were dummy coded for daily reading and for reading several times per week, with reading fewer than several times per week as the referent group. This analysis examined separately the associations between child outcomes and daily reading, reading several times a week, and reading concurrently versus at a previous age (Table 5).

With respect to the frequency of bookreading and outcomes at both 14 and 24 months, coefficients were significant for reported reading several times a week, as well as for daily reading (for 14-month CDI comprehension and production, 24-month CDI production, and 24-month MDI, but not for 14-month MDI). However, for 36-month outcomes with earlier reading controlled, there were no significant effects. With respect to timing and language outcomes, bookreading at 14 months failed to add any predictive value to 24-month outcomes above the effects of concurrent bookreading. However, reading daily at 24 months did marginally predict PPVT-III scores at 36 months, suggesting that 24-month daily reading may associate with both concurrent and later outcomes, as shown in Table 5. On the other hand, concurrent 36-month daily reading was associated with TVIP scores and MDI scores among children completing the assessments in Spanish $(S B=.26$ and $.27, p=.07$ and .08 , respectively), again suggesting that, for Spanish-speaking children, relations between reading and outcomes may manifest later in the infant-toddler period than appears to be the case for English-speaking children.

Daily reading from 14 to 36 months of age. We asked whether children's language and cognitive outcomes at age 36 months might be more strongly statistically predicted by a pattern of daily reading over time than by concurrent reading frequency alone, as reported by mothers. To explore this possibility, we created three dummy variables to represent patterns of daily reading: daily reading at three ages, reading several times a week at three ages, and reading several times a week at only two ages. The comparison was rarely reading (i.e., reading less than several times a week at two or more ages). Table 6 shows that daily reading at three ages was significantly associated with 36-month PPVT-III and MDI outcomes in the English-speaking group. Less consistent reading frequency did not predict language or cognitive outcomes. Because few of the Spanish-speaking children were read to daily at multiple time points, we examined the effect of daily reading at any of the three ages for that subgroup versus all other lesser frequencies of reading. Spanish-speaking children who had been read to daily during at least one of the measurement periods had significantly higher TVIP and MDI scores than did Spanish-speaking children whose parents reported never reading to them daily at any age. Table 6 also presents control variables, as preparation for simulated means discussed later.

\section{A Path Model to Explore Reciprocity of Influence}

We conducted regression path analyses to explore reciprocity of influence in child abilities and bookreading and to further understand effects related to timing. We hypothesized five pathways to maternal reading and children's language and cognitive outcomes at 36 months: (a) a direct path from early to later reading, (b) a direct path from early to later child language and cognitive abilities, (c) paths from maternal reading to concurrent child language and cognitive outcomes, (d) paths from maternal reading to later child language and cognitive outcomes, and (e) paths from child language ability to later maternal reading.

We used the same maternal and child control variables in the path model as in the previous analyses and created a single index for reading at each age: rarely reading $=0$, reading several times a month $=1$, reading several times per week $=2$, and daily reading $=3$. It was necessary to create a continuous variable in order to complete the regression path analyses that would provide a test of our proposed model. Although intervals between reported levels of reading were not necessarily equidistant, we considered the use of a continuous variable justifiable in examining the relative effects of reading and a child's emerging language on later ability and later reading (see Yarosz \& Barnett, 2001, for a similar approach). We explored paths to all child outcomes at 36 months of age in the English-speaking sample. Significance levels were divided by the total number of possible paths (13), yielding a required significance level of .004 for each pathway. The path model was particularly rigorous for 24- and 36-month outcomes because it included all previous vocabulary and reading levels as well as all control variables. 


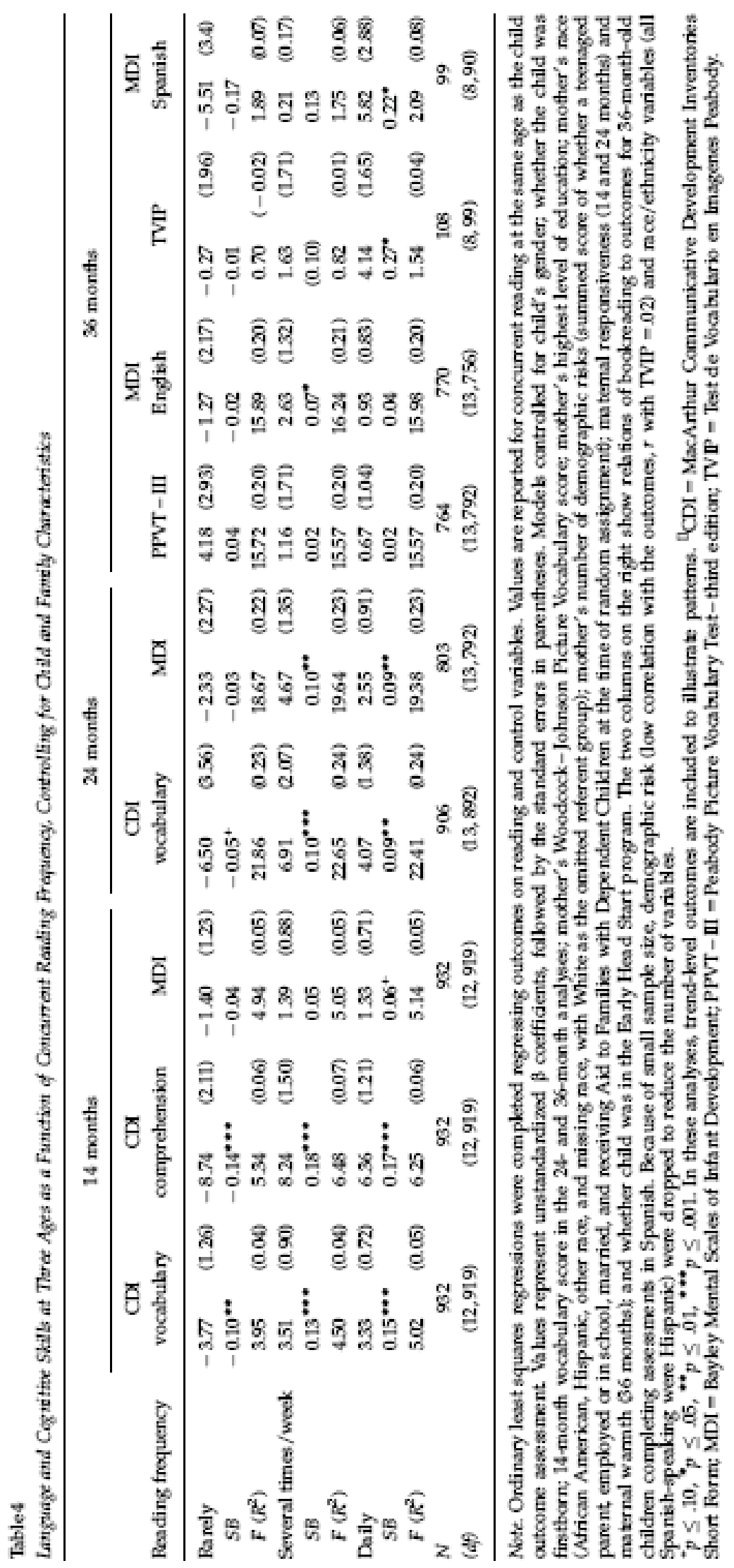




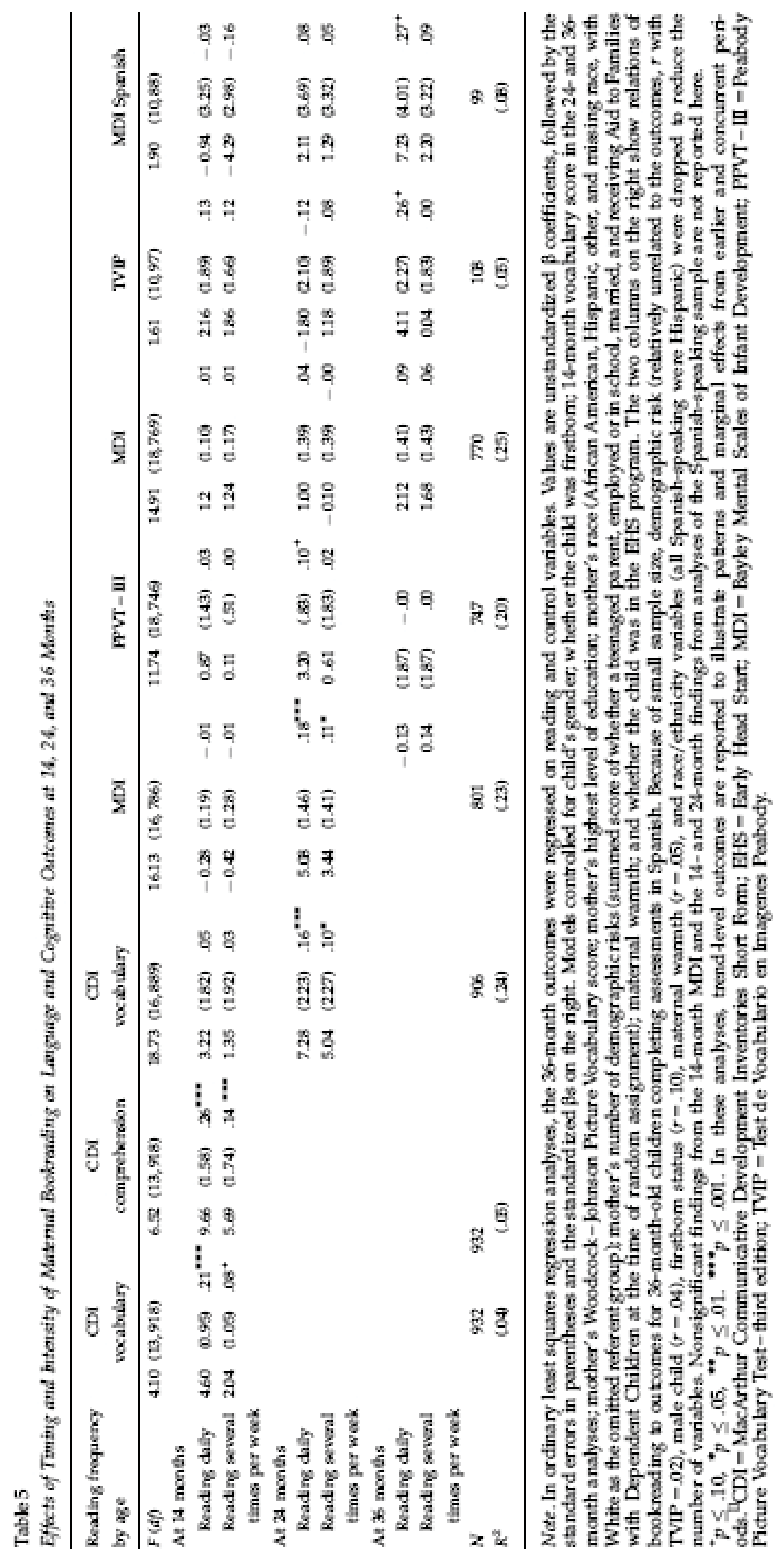


Mother-Child Bookreading in Low-Income Families

Table6

Rouding Pattons as Pralictors of 36-Morth Language and Cognitize Ondcomes

\begin{tabular}{|c|c|c|c|c|c|c|c|c|c|c|c|c|}
\hline \multirow{2}{*}{$\frac{\text { Predictor }}{\text { (White, onitted) }}$} & \multicolumn{3}{|c|}{ PPVT-III } & \multicolumn{3}{|c|}{ MDI English } & \multicolumn{3}{|c|}{ TVP } & \multicolumn{3}{|c|}{ MDX Spanish } \\
\hline & & & & & & & & & & & & \\
\hline African American & -200 & $(1.20)$ & -06 & -4.40 & $0.95)$ & $-.18^{* * *}$ & & & & & & \\
\hline Hispanic & 0.19 & (2.14) & $\infty$ & -129 & $(1.68)$ & -.08 & & & & & & \\
\hline Other race & -1.18 & $(2.42)$ & $-\infty 2$ & -2.39 & $(1.90)$ & -04 & & & & & & \\
\hline Race missing & 309 & $(4.95)$ & 02 & 1.73 & (2.81) & 02 & & & & & & \\
\hline Risk & -0.63 & $(0.57)$ & -04 & -0.29 & $0.45)$ & $-\infty 2$ & & & & & & \\
\hline Matemal verbal ability & 0.35 & $(006)$ & $23 * *$ & 0.17 & $(0.04)$ & $.15^{* * *}$ & 0.03 & $(0.10)$ & 0.04 & 0.10 & (0.18) & .07 \\
\hline Matemal highest ed & 1.13 & $(0.31)$ & $.13^{* * *}$ & 1.01 & $0.23)$ & $.16^{* * *}$ & 0.20 & $(0.22)$ & 0.10 & 0.48 & $(0.37)$ & .15 \\
\hline Finstbom & -0.32 & (1.05) & -01 & -0.75 & (0.84) & -03 & 0.61 & (1.51) & 0.04 & -0.12 & $(2.54)$ & -01 \\
\hline Make & -2.93 & $(1.00)$ & $-.10^{* *}$ & -1.56 & $0.79)$ & $-06^{*}$ & 0.22 & (1.42) & 0.02 & 0.35 & $(2.42)$ & .02 \\
\hline EHS program & 2.56 & $(1.00)$ & $\mathbf{a s}^{*}$ & 1.52 & $0.79)$ & $06+$ & 1.40 & (1.44) & 0.10 & 4.54 & $(2.45)$ & $.19^{\circ}$ \\
\hline Matemal warnth & 2.56 & $(0.63)$ & $.14^{* * *}$ & 2.77 & $0.51)$ & $.18^{* * *}$ & -0.49 & (1.22) & -0.04 & 1.26 & $(2.41)$ & .05 \\
\hline Always daily resding & 4.52 & $(208)$ & $.14^{*}$ & 3.40 & $(1.57)$ & $.13^{*}$ & & & & & & \\
\hline Read. sevenal tims / wk & 1.85 & $(200)$ & 06 & 1.51 & $(1.47)$ & $\theta 7$ & & & & & & \\
\hline Some several fimes/wk & 1.61 & $(2.10)$ & 04 & 1.48 & (1.58) & 05 & & & & & & \\
\hline Any daily read. Span) & & & & & & & 3.01 & (1.46) & $0.21^{*}$ & 5.10 & $(2.53)$ & $21^{*}$ \\
\hline 14-manth vocabulary & 0.17 & $(005)$ & $.12^{* * *}$ & 0.09 & (0.04) & $05^{*}$ & -0.08 & (a.11) & -0.05 & 0.21 & $(0.17)$ & .12 \\
\hline$N$ & & 765 & & & 770 & & & 105 & & & 99 & \\
\hline$R^{2} F($ d $f$ ) & 0.20 & $140 \%$ & $(15,749)$ & 0.21 & 14.23 & $(15,754)$ & 0.01 & 1.11 & $8,99)$ & 0.05 & 206 & $(8.90)$ \\
\hline
\end{tabular}

Note. In ordinary lesst squares regression analyses, the 36-month outconks were regresed on reading and control variables. Values are u nstanda rdized $\beta$ coefficients, followed by the standard enors in parentheses and the standardized $\beta$. Models controlked for child's gender; whether the child was firstborr 14-month vocabulary, mother's Woodoock-bohnson Picture Vocabulary score; mother's highest level of education; mother's rsce (African American, Hispanic, other, and missing race, with White as the omitted referent group); mother's number of demographic risks (summed score of whether a teenaged parent employed or in school, married, and receiving Aid to Fanilies with Dependent Children at the time of random assignmert); moternal warmth; and whether dild was in the Early Hesd Start program. Analyses for Sparish spes ling (two colunus on the right) did nok cantrol for race/ethnicity variables and risk to red uce the total number of varis at kast several times a week at three times (but nok daily three times), and reading at kast several times a week for two of the three times. For all, the onitted referent group was reading kss than several times a week for two of the three fims messured (rarely reading). For Spanish speaking, a pattem variable of resding ance during the study period was created (compared with never daily reading). $* p \leq 05, * 0 \leq 01, * * p \leq 001$

MDM - Bayley Mental Scales of Infont Development; PPVT-III = Peabody Ficture Vocabulary Test-third edition; TVIP = Test de Vocabulanio en Inagenes Peabody.

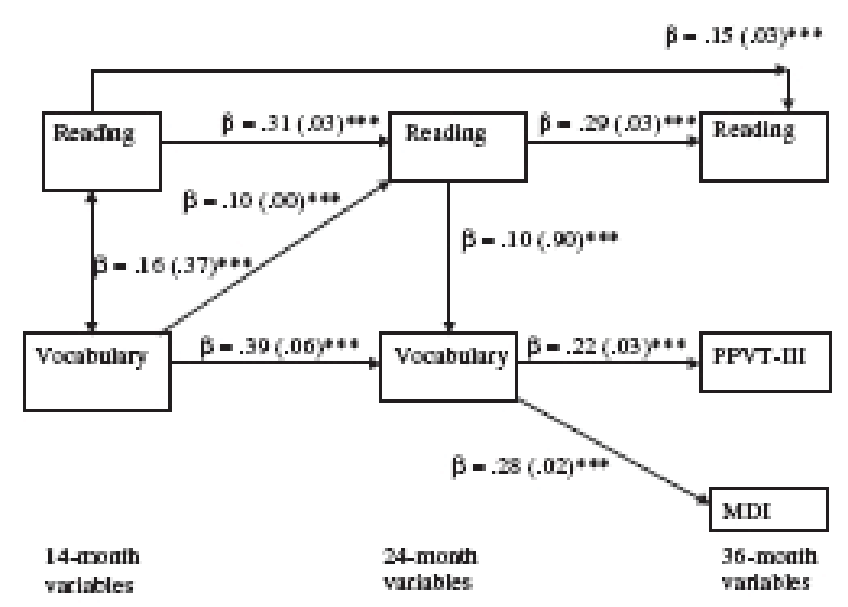

Figure 3. Path model for Engish-speaking sample. *** $p \leq 004$. Noke that all the paths included in the figure moet the criterion of significance, $p \leq 004$. Figures are stand ard ixed $\beta$ cocfficients (SFi). MDX = Bayley Mental Saks of Infant Development; PPVTIII = Peabody Picture Vocabubry Test-third edition.
The first two pathways in the regression path model supported the first and second hypotheses (Figure 3). Reading at each age predicted reading at the subsequent age, and child verbal ability at each age predicted ability at the next. In addition, 14-month reading predicted 36-month reading above and beyond the effects of 24-month reading. In the third hypothesized path, concurrent reading was significantly associated with language development at 14 and 24 months but was not associated with outcomes at 36 months, with the many controls in the model. Next, vocabulary development at 14 months was related to reading at 24 months; a similar pattern was observed for 14-month vocabulary and 36-month reading, but results did not reach path model significance. Finally, reading at 14 and 24 months did not contribute to language development at the subsequent age above the effects of concurrent reading. These findings point to four simultaneous and complementary pathways: (a) early maternal 
reading leading to later reading, (b) early child vocabulary leading to later language and cognitive ability, (c) 14and 24-month maternal reading associating concurrently with child verbal ability, and (d) 14-month child vocabulary development leading to 24-month maternal reading, with reading reported by the mother. Effects at 14 and 24 months are direct, whereas at 36 months effects appear to be indirect, occurring through earlier reading and vocabulary. The model suggests that paths are set in motion early, by 14 or 24 months. ${ }^{8}$

\section{Simulated Means}

We were interested in simulating potential advantages of reading combined with the overarching Early Head Start intervention. We computed simulated means from regression coefficients to show how language and cognitive scores for children of mothers with very low verbal ability ( $\leq 85$ on the WJ test of verbal ability) and somewhat higher verbal ability $(>85)$ relate to cumulating three potential supports or interventions (Early Head Start, daily reading, and completing high school). These are variables that had been significant in the previous regression analyses. We created dichotomous variables for education (high school completion or not) and for reading (for English-speaking children, daily reading at three assessment periods; for Spanish-speaking children, daily reading at one assessment period). As Table 7 shows, each of these three support variables adds about 1-4 points to children's predicted standardized cognitive and language scores for both English- and Spanish-speaking children and for children of both mothers with higher and lower verbal ability.

\section{Summary of Findings}

Table 8 summarizes research questions, analyses, and findings. This study demonstrated that a majority of mothers reported they were reading to infants and toddlers with some frequency. At the same time, there was wide variability among low-income mothers in patterns of bookreading, with mothers who were White, those who were more highly educated, and those who were parenting firstborn children reading daily more consistently over the three ages than were their counterparts. In regression analyses to examine relations between reading and child outcomes, we controlled for the variables of race/ethnicity, demographic risk, maternal education and verbal ability, gender, birth order, Early Head Start enrollment,

Table7

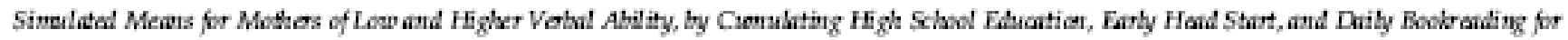
36-Moush Language and Cogreitice Measurs

\begin{tabular}{|c|c|c|c|c|}
\hline \multirow[b]{2}{*}{ Group } & \multirow[b]{2}{*}{ PPVT - III } & \multirow{2}{*}{$\frac{\text { MDI }}{\text { Engdish }}$} & \multirow[b]{2}{*}{ TVIP } & \multirow{2}{*}{$\frac{\mathrm{MDA}}{\text { Spanish }}$} \\
\hline & & & & \\
\hline Low verbl ability (no HS, no EHS, no daily resding) & 73.55 & 85.70 & 91.95 & 83. 19 \\
\hline Low verbal ability $+\mathrm{HS}$ & 7760 & 83.90 & 92.85 & 87.73 \\
\hline Low verbal ability + HS +EHS & 80.26 & 90.44 & 94.29 & 91.80 \\
\hline Low verbal ability + HS +EHS+ daily resding & 83.78 & 92.85 & 97.11 & 94.60 \\
\hline Higher verbal ability (no HS, no EHS, no daily reading) & 81.72 & 88.89 & 95.67 & 98.95 \\
\hline Higher verbal ability+ HS & 84.11 & 91.03 & 9725 & 94.87 \\
\hline Higher verbal ability+ HS+EHS & 86.77 & 95.40 & 98.07 & 100.79 \\
\hline Higher verbal ability+ HS+EHS+daily resding & 90.23 & 96.04 & 100.83 & 103.57 \\
\hline Sample average & 84.29 & 91.83 & 94.73 & 90.17 \\
\hline$N$ & 765 & 770 & 108 & 99 \\
\hline
\end{tabular}

Note. Using regression coefficients from the previous analysis (Table 6), regression-simula tod mears were calculated for all combinations of low and higher verbal ability ( $\leq 85$ on the Woodoock-Johnson test of verbal ability vs. $>85$ ); HS education ( $<$ HS vs. $>$ HS); EHS program or not and whether the mother reportad resding daily to the child at each of the three irterviews. Models for Enghish-spealing children controlkd for child gender; whether the child was firstbom; 14-month vocabulary; mother's race (African American, Hispanic, other, and missing rsce, with White as the cmitted referent group); mother's number of demographic risks (summed score of whether a teenaged parent, employed or in school, married, and rexeiving Aid to Families with Dependent Child ren at the time of random assignment; and matemal wamth. Modek for Spanish-spes king children did notinchude mother's rsce/ethnicity or risk to reduce the number of varisbles in this smoller sample. For simplicity only eight of the 16 possible combinations are reported here. Other combination pattems were very sinuilar to those seen here.

EHS - Early Hesd Start; HS - high school; MDX - Bayky Mental Scakes of Infant Development; PPVT - III = Peabody Picture Vocabulary Test-third edition; TVIP = Test de Vocabulario en Imagenes Peabody. 


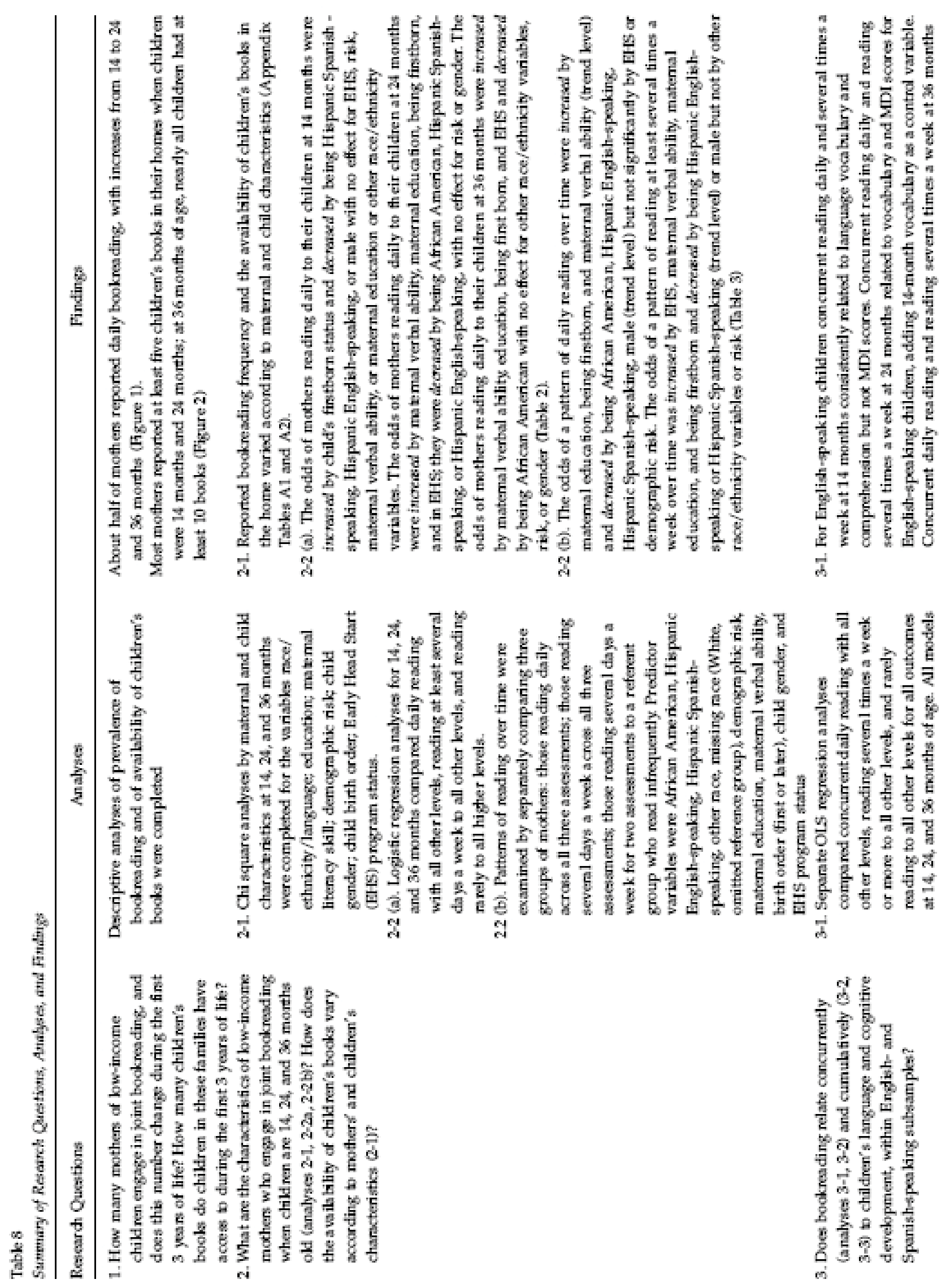




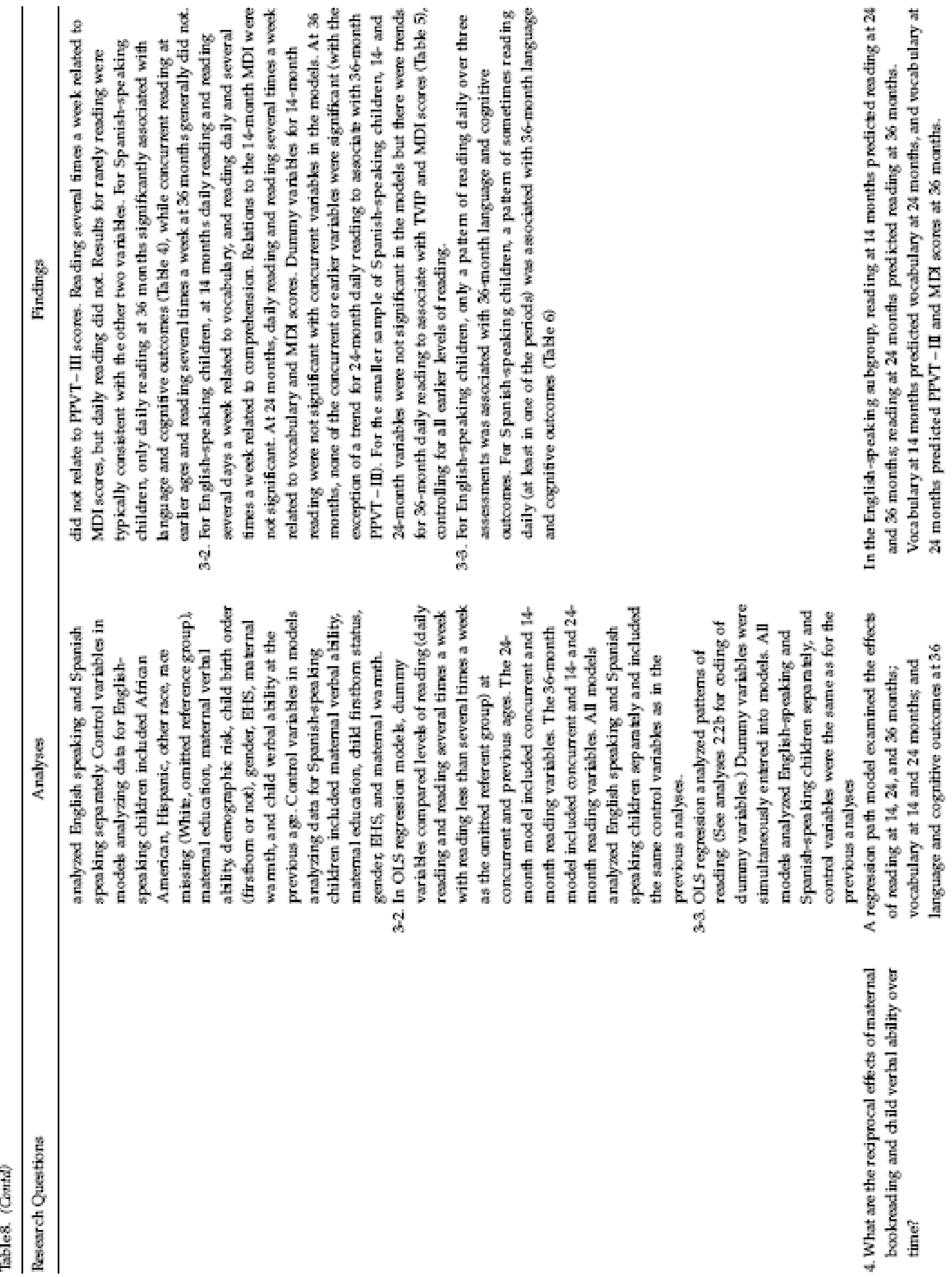




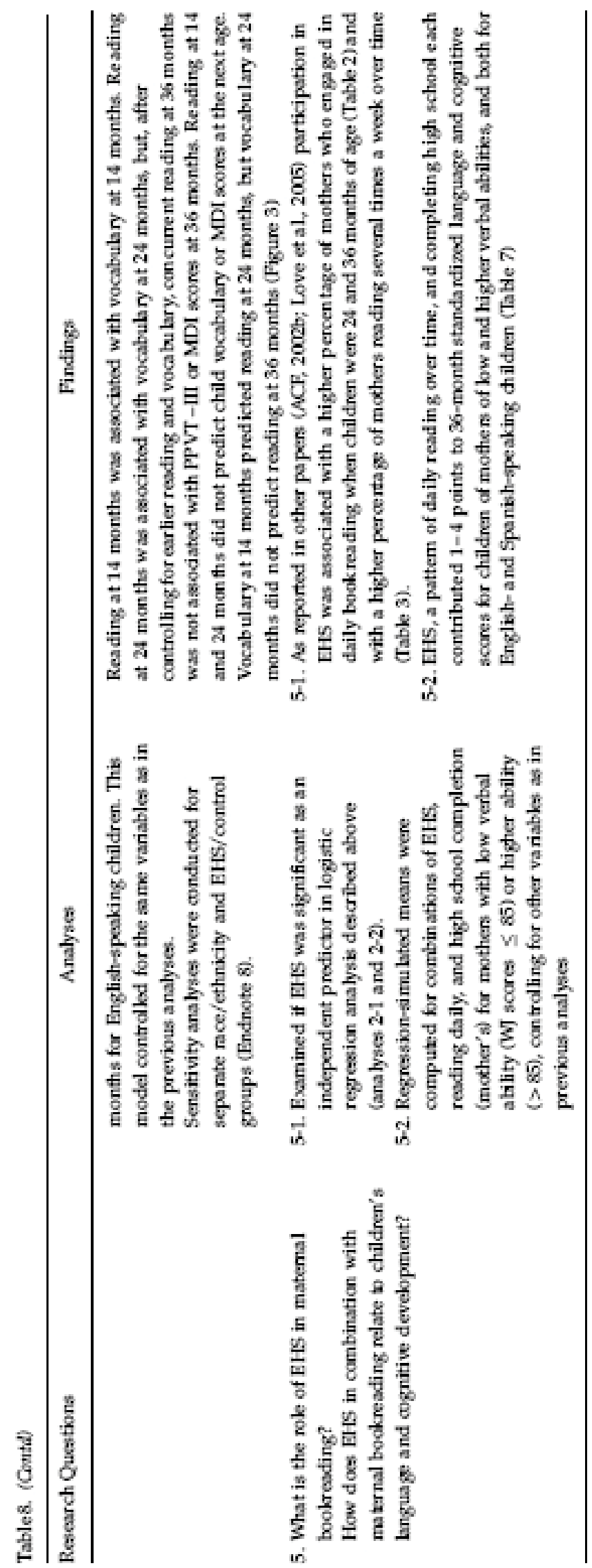

and maternal warmth. In the English-speaking group, at 14 months, reading several times weekly or reading daily was significantly related to vocabulary and comprehension. Findings were similar for vocabulary and MDI scores at 24 months, even after controlling for children's 14-month vocabulary. A pattern of daily reading over three data points significantly related to child language and cognitive outcomes at 36 months. Reading daily at a minimum of one of the periods predicted language outcomes for Spanish-speaking children. Regression path analyses showed paths from early reading to later reading, early vocabulary to later child language outcomes, and 14-month vocabulary to 24-month reading. Paths for concurrent reading revealed associations with vocabulary at 14 and 24 months. Simulated means revealed that, for children of mothers with low and higher verbal ability (above and below a standardized score of 85), participation in Early Head Start, daily bookreading, and mother's completion of high school each contributed between 1 and 4 points to standardized outcomes at a child age of 36 months for both English- and Spanish-speaking children.

\section{Discussion}

Findings from this study highlight the role of maternal bookreading with children during the dynamic period of early language learning from 14 to 36 months of age. For English-speaking children, the period from 14 to 24 months appears to be one during which child language and maternal bookreading may together begin a "snowball" effect for subsequent bookreading experiences and development. While less can be said about Spanishspeaking Hispanics, owing to smaller sample size, positive associations between bookreading and children's language and cognitive development were apparent around 36 months of age. The study underscores the importance of targeting preliteracy interventions for low-income English-speaking children much earlier than previous research has suggested and points to the need for further study to determine optimal intervention timing for Spanish-speaking infants and toddlers. We address each of the specific findings in turn.

\section{Reading to Children}

The good news is that, by 14 months and increasing with age, nearly all of the study's low-income children were 
read to with some regularity. Consistent with findings from Head Start samples of children 3-5 years of age in which weekly reading rates are similar to those for middle-income children (ACF, 2002a), reported reading rates for the low-income infants and toddlers did not fall below national averages (Britto et al., 2002). Thus, the message about the importance of bookreading is reaching families across a spectrum of U.S. society (National Academy of Education, Commission on Reading, 1985), at least among parents in programs where reading is stressed.

However, enormous variation existed across families. Although many of the low-income mothers in our sample were reading to their infants and toddlers every day, some were not. Notably, children of color were less likely to be read to daily, a difference that has been reported elsewhere (ACF, 2002a; Bradley et al., 2001; Yarosz \& Barnett, 2001). Children's language experiences might be affected by cultural differences (e.g., perhaps Hispanic children are told rather than read stories) and might explain why both English- and Spanish-speaking Hispanic mothers read significantly less frequently to their 14-month-olds than did mothers in other groups. However, the finding that reading daily for at least some period during the first 3 years of life related to TVIP receptive vocabulary and the MDI for Spanish-speaking children underscores the importance of investigating reading across cultural groups. Spanishspeaking Hispanic families had far fewer children's books than did other families in the sample, suggesting that other non-English-speaking families may also have limited access to children's books in their home languages. Although, in the current study, we analyzed data from all Englishspeaking children together to garner a picture of reading experiences within a sample of low-income families, we acknowledge the value of analyses that explore reading, its meaning, and the availability of books for distinct racial/ ethnic groups.

Not surprisingly, maternal education was strongly associated with bookreading (see also Lyytinen et al., 1998; Scarborough \& Dobrich, 1994), and maternal verbal ability was related to bookreading. Bookreading with children is part of a broader pattern of rich verbal input to children that is characteristic of mothers with strong verbal skills and high levels of education (Hoff, 2003). Intervention programs such as Early Head Start may need to provide additional supports to parents with low verbal/literacy skills and lower levels of education to ensure that children of these parents receive the language stimulation they need for optimal language development.

Characteristics of children also influenced bookreading. Firstborn children were more likely to be read to daily than were later-born children, perhaps because the former had fewer competing demands for their time. Consistent with gender differences in early language development (Teale, 1986), boys were less likely to be read to daily than were girls at 14 months, although gender differences narrowed at later ages. However, boys still were overrepresented among children who were rarely read to even at 36 months, and they generally experienced less reading over time. It is possible that parents perceive boys as less verbal, more active, or harder to engage in reading activities. Additional research is needed to reveal the parental perceptions and beliefs that underlie gender-related differences and to determine whether limitations in early preliteracy experiences are associated with later school and reading difficulties for low-income boys.

Participation in the Early Head Start program was associated with increased bookreading at ages 2 and 3, as reported elsewhere (ACF, 2002b; Love et al., 2005). This finding demonstrates that broad comprehensive parent-child interventions outside of formal educational settings, in addition to interventions that specifically target bookreading behaviors, can influence literacy environments (Whitehurst et al., 1994). Early Head Start participation was not associated with bookreading among children at age 14 months, as many children entered the program late during their 1st year of life. However, Early Head Start participation was related to a pattern of reading at least several times a week over the study period.

\section{Reading and Children's Language and Cognitive Development}

Our analyses show that, even after controlling for a range of parent and child factors, concurrent reading is associated with child language. Associations were strong for child vocabulary production and comprehension at 14 months and for vocabulary production at 24 months. Moreover, reading daily or reading several days weekly was related to language outcomes. Thus, the relations between bookreading and language outcomes appear to be strong and direct during the first 2 years of life. Given that we controlled for earlier language, reading, and other variables, the 24month findings were particularly notable. 
At 36 months, the picture for language outcomes became more complex, with earlier (24-month) daily reading having a stronger association than concurrent reading with Englishspeaking children's receptive vocabulary. Daily reading over time was also associated with 36-month language scores. However, concurrent bookreading no longer related to child measures by 36 months, when controls for earlier reading were included in models. These patterns, combined with findings from the path model, lead to the conclusion that associations between reading and language outcomes may be more indirect by 36 months. This finding does not diminish the importance of reading to children at age 3 . Rather, it reinforces the importance of a pattern that begins early and continues through the preschool years.

Concurrent reading at 14 months was not significantly associated with general cognitive skills, perhaps because the 14-month MDI assessment includes a more limited number of language and communication items than the 24and 36-month MDIs. However, the relationship between bookreading and cognitive development at 24 months was quite robust, even after controlling for earlier vocabulary and language experiences. Again, a pattern of daily reading over time was the strongest predictor of the 36-month cognitive outcome, once more suggesting more indirect effects of bookreading as children enter the preschool years and the importance of continued daily reading from 14 to 36 months of age for English-speaking children.

Conversely, daily reading was associated with both language and cognitive outcomes for Spanish-speaking children at 36 months but not earlier, suggesting different patterns of relations between early literacy experiences and language and cognitive development for children from minority linguistic or cultural backgrounds. It is possible that associations found between reading and child language and cognitive development among Spanish-speaking children at ages later than for English-speaking children were due to the reduced access to children's books in these families, at all ages and particularly at 14 months. Because there are many Spanish-speaking young children in the United States, it will be important to continue to study the role of bookreading, as well as other early literacy experiences, in fostering the language and cognitive development of these children.

Path analyses yielded direct and indirect relations between reading and English-speaking child outcomes at the three ages. The metaphor of a snowball seems to fit the way in which reading frequency may relate to later outcomes- exposure to reading supports early vocabulary gains that, in turn, appear to lead to more reading and vocabulary growth. Thus, bookreading frequency appears to associate with early language and cognition through multiple processes that gather momentum, beginning at least from age 14 months. While this study cannot determine the direction of influence between reading and children's language skills at 14 months, the link found from 14-month vocabulary to 24month maternal reading suggests that, in the earliest stages of children's productive language, more linguistically advanced children encourage parents' engagement in joint bookreading as well as benefit from it. What might a mother be responding to by reading to her child? At 14 months, it might simply be the fact that her child is "talking" and thus would likely benefit from, and be responsive to, the communicative exchanges offered by joint bookreading. Alternatively, parents might be tuned in more specifically to their child's vocabulary comprehension and production skills, because language learning at this age concentrates on word learning. Bookreading frequency later in toddlerhood may conceivably reflect parents' sensitivity to children's broader language skills (NICHD, 2005). The transactional relationship between the child and the environment that our findings suggest is in keeping with the developmental model described by Sameroff and Fiese (2000) and hypothesized previously in the bookreading literature (Lyytinen et al., 1998; Scarborough \& Dobrich, 1994).

The use of simulated means highlighted the additive effects of different combinations of potential intervention experiences, which was important given that the context for the current study was the Early Head Start intervention study. Three supports, potentially subject to modification, were highlighted in these simulations: Early Head Start enrollment, daily maternal bookreading, and high school completion by mother. Means were simulated for mothers varying in verbal ability (those scoring at or below 85 on the WJ and those closer to average ability) and in English- and Spanishspeaking subgroups. Each of the three variables added approximately 1-4 points to standardized score outcomes in all groups, suggesting that broad comprehensive child development programs such as Early Head Start could potentially boost the current level of child language and cognitive impacts by embedding targeted interventions that promote daily bookreading and parental high school completion, even for very low-ability mothers, a group that has been little studied but that is served by programs such as Early Head Start. 


\section{Limitations}

Several cautions must be applied in interpreting the current findings. First, we relied on mothers' reports of their bookreading with their children, which may be subject to social desirability influences, and could belie intention versus behavior, an issue that is underscored by a positive skew in the data. However, the measure of parental bookreading used in this study is consistent with the measure used in most other large studies, including FACES (ACF, 2003), National Household Education Surveys (Nord, Lennon, Lui, \& Chandler, 1999), and the Early Childhood Longitudinal Study-Birth Cohort (ECLS-B; NCES, 2005), all of which have consistently demonstrated modest, positive associations between parental daily bookreading and children's development. The findings in our own study were also internally consistent, e.g., differences between the program and control group in bookreading were similar in effect sizes to program and control differences for other parenting measures collected by videotaped and on-site observations (ACF, 2002b). We chose to address the positive skew in the data, to some extent, by treating the variables as dichotomous in initial analyses. It is important to note that the study recruited parents of infants who were seeking an intervention program; these parents may be a special subset of low-income parents. It is also possible that low-income parents of very young children "count" as bookreading joint attention to books during the course of toddler play, particularly considering that wordless and simple picture books, typical of books for infants and toddlers, may be somewhat accessible and present few literacy demands to parents such as those in the current study. Thus, despite some concerns, we think parental report remains the best option for estimating bookreading frequency across large samples of participants, short of large-scale ethnographic work or video-supported time sampling in participants' homes (each of which raises its own issues of feasibility and participation burden). Nonetheless, appropriate caution should be exercised in interpreting the results reported here and elsewhere.

Similarly, we relied on maternal report of children's vocabulary at the earliest ages, a common and sometimes recommended (Diamond \& Squires, 1993) strategy given the difficulties of direct assessment of very young children's vocabulary. Whereas child language researchers in general have tended to study very small samples of children and to rely on diary studies (also a form of parent report) and/or analysis of spontaneous speech to assess the vocabulary of very young children, such approaches are not feasible in large samples of participants. Some support for the validity of the CDI with low-income families is offered by a previous study (Pan et al., 2004), in which moderate to strong associations were found between spontaneous speech samples and parent report. Parallel findings in the current study for CDI and standardized cognitive scores offer reassurance that maternal report is not radically divergent from measures derived from direct assessment. Moreover, in the pattern, path, and simulated models, the outcome measures were the MDI and PPVT/TVIP, which provided direct tests of children's cognitive and language status.

Another limitation is the exclusive focus on reading between mothers and children. Many people other than mothers (e.g., fathers, grandparents, older siblings, other household members, and child-care providers) may read to infants and toddlers. For example, Dickinson and De Temple (1998) found that $83 \%$ of low-income mothers reported people other than themselves read to their 3-yearold children. Britto et al. (2002) reported that $29 \%$ of fathers were daily readers. Given the dearth of research on father-child reading (Gadsden, 2000), in future reports we hope to expand the picture to include fathers and other caregivers.

Furthermore, frequency of bookreading is only one way of conceptualizing the bookreading experience. Differences among families in the quality of talk during bookreading can be of crucial importance, even without variations in bookreading frequency, intensity, or timing. Whitehurst et al. (1994) demonstrated positive effects on low-income children's vocabulary when parents and teachers were instructed in dialogic reading, in which the child learned to be the storyteller and the adult became the facilitator of dialogue about the story. In one longitudinal study of low-income families (De Temple \& Beals, 1991), the incidence of nonimmediate, interpretive talk during bookreading related as strongly to child outcomes as did the reported frequency of bookreading, and this type of talk was much less frequent among young, welfare-dependent, single mothers (De Temple \& Snow, 1998) than among a more advantaged population. Less is known about how the quality of bookreading relates to outcomes for infants and toddlers, but at least one study documented meaningful variation in how expressively mothers read to their toddlers (Britto \& Brooks-Gunn, 2001). However, infants and toddlers are unlikely to participate in joint 
bookreading activity with any frequency if the bookreading adult does not engage them in joint attention and does not converse or read to them in an engaging fashion.

Finally, we do not suggest that bookreading represents the totality of children's home literacy experiences. Storch and Whitehurst (2001) found that several indexes of the home literacy environment, as well as the frequency of shared reading, were related to children's vocabulary and conceptual knowledge in an ethnically diverse Head Start population. Others propose that three dimensions of the home language and literacy environment-language and verbal interactions, the learning climate, and the socialemotional climate-relate to children's development (Britto \& Brooks-Gunn, 2001; Rodriguez et al., 2005). Literacy materials have also received attention. In particular, identification of specific children's books is a more stable predictor of child language than parent report of bookreading in the preschool years (Sénéchal \& LeFevre 2002; Sénéchal et al., 1998). However, it is our view that during the infant and toddler years, availability of books, at least at a minimal level, is a requirement of shared bookreading, and that very young children are not likely to experience gain from books out of the context of shared reading.

Clearly, many elements (materials, maternal sensitivity, specific opportunities to practice with adults seeking to understand and respond to the meaning of the child's communications) comprise important aspects of the languagelearning environments of young children. In the context of broader language learning, shared bookreading between parents and toddlers may provide a unique venue for focused language exchange, enabling responses to child language and thinking and providing exposure to the maternal language, scaffolding, and interaction that De Temple and Snow (2003) and others describe as promoting child vocabulary, conceptual understanding, and possibly other aspects of language found to relate to subsequent communicative and literacy competence among older children (NICHD, 2005).

As a final consideration, it is important to bear in mind that the sample for the current study consisted of families in poverty. On the one hand, the families in our study did volunteer to participate in an intervention program, and those retained in the current study were slightly more advantaged than those in the overall Early Head Start research sample. We would have expected to observe even greater variability in outcomes if more respondents at the bottom end of the range had been included. On the other hand, we would also expect greater variability when adding more advantaged respondents from a typical U.S. sample. Thus, the relatively robust direct and indirect relations between bookreading and outcomes found within our low-income sample are notable.

To summarize, this investigation makes several methodological and empirical contributions to the study of the preliteracy environments of low-income children. These include (a) documenting considerable variation in the reading patterns among subgroups within a low-income sample, including study of the reading patterns and availability of books among Spanish-speaking mothers of children younger than age 3, (b) revealing associations between bookreading and English-speaking low-income children's development in lagged-effects models, while also controlling for a range of other factors, (c) demonstrating that bookreading is associated with the language development of Spanish-speaking children, (d) providing a heuristic for studying the pathways by which early and intensive bookreading experiences may both support and respond to language development, and (e) documenting that early bookreading among mothers of very low verbal ability, as well as among those with higher verbal ability, may be one of several potential factors that could be targeted for special focus in the context of other interventions (such as the Early Head Start comprehensive intervention program). The study findings underscore the value of emphasizing bookreading experiences for low-income infants and toddlers and suggest subpopulations for which access to books and encouragement to read could be intensified. However, we believe that the main contribution of this study is to illustrate the important associations with bookreading experiences, particularly during the period from 14 to 24 months of age for English-speaking children and before 36 months of age for Spanish-speaking children. The study's findings point to the phase of early and rapid language learning as a critical period for targeting bookreading, to enhance and in response to children's growing vocabularies. Dynamic processes set in motion during this phase appear to have important developmental implications for low-income children growing up in a highly literate society.

\section{References}

Administration for Children and Families (ACF). (2002a). A descriptive study of Head Start families: FACES 1997 (Tech Rep. I). Washington, DC: Author. 
Administration for Children and Families (ACF). (2002b). Making a difference in the lives of infants and toddlers and their families: The impacts of Early Head Start. Washington, DC: Author

Administration for Children and Families (ACF). (2003). Head Start FACES (2000): A whole child perspective on program performance-fourth progress report. Washington, DC: Author.

Administration on Children, Youth and Families (ACYF). (2001). Building their futures: How Early Head Start programs are enhancing the lives of infants and toddlers in low-income families. Washington, DC: Author.

Anderson, A. B., Teale, W. H., \& Estrada, E. (1980). Low-income preschool literacy experiences: Some naturalistic observations. The Quarterly Newsletter of the Laboratory of Comparative Human Cognition, 2, 59-65.

Arriaga, R. I., Fenson, L., Cronan, T., \& Pethick, S. J. (1998). Scores on the MacArthur Communicative Development Inventory of children from low- and middle-income families. Applied Psycholinguistics, 19, 209-223.

Bayley, N. (1993). Manual for the Bayley scales of infant development. New York: Psychological Corporation.

Bornstein, M. H., Haynes, O. M., \& Painter, K. M. (1998). Sources of child vocabulary competence: A multivariate model. Journal of Child Language, 25, 367-393.

Bradley, R. H., Corwyn, R., McAdoo, H. P., \& Coll, C. G. (2001). The home environments of children in the United States part I: Variations by age, ethnicity, and poverty status. Child Development, 72, 1844-1867.

Britto, P. R., \& Brooks-Gunn, J. (2001). Beyond shared book reading: Dimensions of home literacy and low-income African American preschoolers' skills. New Directions of Child Development, 92, 71-89.

Britto, P. R., Fuligni, A., \& Brooks-Gunn, J. (2002). Reading, rhymes and routines: American parents and their young children. In N. Halfon, K. T. McLearn, \& M. A. Schuster (Eds.), Childrearing in America: Challenges facing parents with young children (pp. 117-145). New York: Cambridge University Press.

Brooks-Gunn, J., Klebanov, P. K., Liaw, F., \& Spiker, D. (1993). Enhancing the development of low birthweight, premature infants: Changes in cognition and behavior in the first three years. Child Development, 64, 736-753.

Bus, A. G., van Ijzendoorn, M. H., \& Pellegrini, A. D. (1995). Joint book reading makes for success in learning to read: A meta-analysis on intergenerational transmission of literacy. Review of Educational Research, 65, 1-21.

Caldwell, B., \& Bradley, R. (1984). Home observation for measurement of the environment: Administration manual, revised edition. Unpublished manuscript, Little Rock: University of Arkansas.

Clay, M. M. (1979). Reading: Patterning of complex behavior (2nd ed.). Auckland, New Zealand: Heinemann.

Cochran-Smith, M. (1984). The making of a reader. Norwood, NJ: Ablex.

DeBaryshe, B. D. (1993). Joint picture-book reading correlates of early oral language skill. Journal of Child Language, 20, 455-462.

DeBaryshe, B. D. (1995). Maternal belief systems: Linchpin in the home reading process. Journal of Applied Developmental Psychology, 16, 1-20.

Deckner, D. (2002, April). Direct and indirect effects of reading practices on infant language development. Poster session presented at the International Conference on Infant Studies, Toronto, Canada.

De Temple, J. (1999, July). Comments, questions and answers: The influence of maternal literacy and child age on interaction during book reading. Paper presented at the VIIIth International Congress for the Study of Child Language, San Sebastian, Spain.

De Temple, J., \& Beals, D. (1991). Family talk: Sources of support for the development of decontextualized language skills. Journal of Research in Childhood Education, 6, 11-19.

De Temple, J., \& Snow, C. E. (1998). Mother-child interactions related to the emergence of literacy. In M. Zaslow \& C. Eldred (Eds.), Parenting behavior in a sample of young mothers in poverty: Results of the New Chance Observational Study (pp. 114-169). New York: Manpower Development Research Corporation.

De Temple, J., \& Snow, C. E. (2003). Learning words from books. In A. van Kleeck, S. A. Stahl, \& E. B. Bauer (Eds.), On reading books to children: Teachers and parents (pp. 16-36). Mahwah, NJ: Erlbaum.

Diamond, K. E., \& Squires, J. (1993). The role of parental report in the screening and assessment of young children. Journal of Early Intervention, 17, 107-115.

Dickinson, D. K., \& De Temple, J. (1998). Putting parents in the picture: Maternal reports of preschooler's literacy as a predictor of early reading. Early Childhood Research Quarterly, 13, 241-263.

Dunn, L. M., \& Dunn, L. M. (1997). Peabody Picture Vocabulary Test (3rd ed.). Circle Pines, MN: American Guidance Service.

Dunn, L. M., Padilla, E. R., Lugo, D. E., \& Dunn, L. M. (1986). Examiner's manual for the Test de Vocabulario en Images Peabody (Peabody Picture Vocabulary Test) Adaptacion Hispanoamericana (Hispanic American adaptation). Circle Pines, MN: American Guidance Service.

Fenson, L., Dale, P. S., Reznick, J. S., Bates, E., Thal, D. J., \& Pethick, S. J. (1994). Variability in early communicative development (Monographs Nos. 242, 59, 5). Ann Arbor, MI: Society for Research in Child Development.

Fenson, L., Pethick, S., Renda, C., Cox, J. L., Dale, P. S., \& Reznick, J. S. (2000). Short-form versions of the MacArthur Communicative Development Inventories. Applied Psycholinguistics, 21, 95-116

Fuligni, A. S., Han, W., \& Brooks-Gunn, J. (2004). The InfantToddler HOME in the second and third years of life. Parenting: Science and Practice, 4, 139-159.

Gadsden, V. (2000). Intergenerational literacy within families. In M. Kamil, P. Rosenthal, R. Pearson, \& R. Barr (Eds.), Handbook of reading research (Vol. 3, pp. 871-888). Mah- 
wah, NJ: Erlbaum.

Garcia-Coll, C. (1995). Ethnic and minority parenting. In M. H. Bornstein (Ed.), Handbook of parenting: Vol. 2. Biology and ecology of parenting (pp. 189-210). Mahwah, NJ: Erlbaum.

Goldfield, B. A., \& Reznick, J. S. (1990). Early lexical acquisition: Rate, content, and the vocabulary spurt. Journal of Child Language, 17, 171-183.

Hoff, E. (2003). The specificity of environmental influence: Socioeconomic status affects early vocabulary development via maternal speech. Child Development, 74, 13681378 .

Hoff-Ginsberg, E. (1998). The relation of birth order and socioeconomic status to children's language experience and language development. Journal of Child Language, 19, 603-631.

Jones, C., \& Adamson, L. B. (1987). Language use in motherchild and mother-child-sibling interactions. Child Development, 58, 356-366.

Kaderavek, J. N., \& Sulzby, E. (1998). Low versus high orientation toward literacy in children. Paper presented at the annual convention of the American Speech-Language-Hearing Association, San Antonio, TX.

Lewis, M. L., \& Rosenblum, M. A. (1974). The effect of the infant on its caregiver. New York: Wiley.

Liaw, F. R., \& Brooks-Gunn, J. (1994). Cumulative familial risks and low-birthweight children's cognitive and behavioral development. Journal of Clinical Child Psychology, 23, 360-372.

Lonigan, C. (1994). Reading to preschoolers exposed: Is the emperor really naked? Developmental Review, 14, 303-323.

Love, J., Kisker, E. E., Ross, C., Raikes, H., Constantine, J., Boller, K., et al. (2005). The effectiveness of Early Head Start for 3-year-old children and their parents. Developmental Psychology, 41, 885-901.

Lyytinen, P., Laasko, M., \& Poikkeus, A. (1998). Parental contributions to child's early language and interest in books. European Journal of Psychology of Education, 13, 297-308.

McCormick, C. E., \& Mason, J. M. (1986). Intervention procedures for increasing preschool children's interest in and knowledge about reading. In W. H. Teale \& E. Sulzby (Eds.), Emergent literacy: Writing and reading (pp. 90-115). Norwood, NJ: Ablex.

National Academy of Education, Commission on Reading. (1985). Becoming a nation of readers. Washington, DC: Author.

National Center for Education Statistics (NCES). (1993). National Household Education Survey: 1993. Washington, DC: U.S. Department of Education, Author.

National Center for Education Statistics (NCES). (1999). National Household Education Survey: 1999. Washington, DC: U.S. Department of Education, Author.

National Center for Education Statistics (NCES). (2005). Early Childhood Longitudinal Study, Birth Cohort (ECLS-B) methodology report for the 9-month data collection (2001-2002): Volume 1: Psychometric characteristics. Retrieved November 6, 2005, from http://0-nces.ed.gov.library.unl.edu:80/pubsearch/pubsinfo.asp?pubid=2005100.
National Institute of Child Health and Human Development Early Child Care Research Network. (2001). Before Head Start: Income and ethnicity, family characteristics, child care experiences, and child development. Early Education and Development, 12, 545-576.

National Institute of Child Health and Human Development Early Child Care Research Network (NICHD). (2005). Pathways to reading: The role of oral language in the transition to reading. Developmental Psychology, 41, 428-442.

Neuman, S., \& Celano, D. (2001). Access to print in low-income and middle-income communities: An ecological study of four neighborhoods. Reading Research Quarterly, $36,8-26$.

Ninio, A. (1983). Joint book reading as a multiple vocabulary acquisition device. Developmental Psychology, 19, 445451.

Nord, C. W., Lennon, J., Lui, B., \& Chandler, K. (1999). Home literacy activities and signs of children's emergent literacy 1993 and 1999 (NCES Publication No. 2000-026 Rev.). Washington, DC: U.S. Department of Education, National Center for Educational Statistics.

Pan, B. A., Rowe, M. L., Singer, J. D., \& Snow, C. E. (2005). Maternal correlates of growth in toddler vocabulary production in low-income families. Child Development, 76, 763782.

Pan, B. A., Rowe, M. L., Spier, E., \& Tamis-LeMonda, C. (2004). Measuring productive vocabulary of toddlers in low-income families: Concurrent and predictive validity of three sources of data. Journal of Child Language, 31, 587-608

Ramey, C. T., \& Campbell, F. (1991). Poverty, early childhood education, and academic competence: The Abecedarian experiment. In A. Huston (Ed.), Children in poverty: Child development and public policy (pp. 190-221). New York: Cambridge University Press.

Rodriguez, E. T., Tamis-LeMonda, C. S., Spellmann, M., Pan, B., Raikes, H., \& Luze, G. (2005). The formative role of children's literacy experiences across the first three years of life. Unpublished manuscript.

Sameroff, A. J., \& Fiese, B. H. (2000). Models of development and developmental risk. In C. Zeanah (Ed.), Handbook of infant mental health (pp. 3-19). New York: Guilford Press.

Sanson, A., \& Rothbart, M. K. (1995). Child temperament and parenting. In M. Bornstein (Ed.), Handbook of parenting: Vol. 4: Social conditions and applied parenting (pp. 299-321). Mahwah, NJ: Erlbaum.

Scarborough, H. S., \& Dobrich, W. (1994). On the efficacy of reading to preschoolers. Developmental Review, 14, 245302.

Scarborough, H. S., Dobrich, W., \& Hager, M. (1991). Preschool literacy experiences and later reading achievement. Journal of Learning Disabilities, 24, 508-511.

Sénéchal, M., \& Cornell, E. (1993). Vocabulary acquisition through shared reading experiences. Reading Research Quarterly, 28, 360-375.

Sénéchal, M., \& LeFevre, J. (2002). Parental involvement in the 
development of children's reading skill: A 5-year longitudinal study. Child Development, 73, 445-460.

Sénéchal, M., LeFevre, J., Hudson, E., \& Lawson, P. (1996). Knowledge of storybooks as a predictor of young children's vocabulary. Journal of Educational Psychology, 88, 520-536.

Sénéchal, M., LeFevre, J. A., Thomas, E., \& Daley, K. (1998). Differential effects of home literacy experiences on the development of oral and written language. Reading Research Quarterly, 32, 96-116.

Snow, C. E. (1987). Factors influencing vocabulary and reading achievement in low-income children. In R. Appel (Ed.), Toegepaste Taalwetenschap in Artikelen, Special 2 (pp. 123128). Amsterdam: Anéla.

Snow, C. E. (1998). Overview of reading and literacy initiatives: Hearings before the Senate Committee on Labor and Human Resources, 105th Congress, 2nd session. Retrieved March 22, 2004, from http://commdocs.house.gov/committees/edu/hedcew5-114.000/hedcew5-114.htm.

Snow, C. E., Arlman-Rupp, A., Hassing, Y., Jobse, J., Joosten, J., \& Vorster, J. (1976). Mothers' speech in three social classes. Journal of Psycholinguistic Research, 31, 424-444.

Snow, C. E., Burns, M. S., \& Griffin, P. (1998). Preventing reading difficulties in young children. Washington, DC: National Academy Press.

Snow, C. E., \& Goldfield, B. A. (1983). Turn the page please: Situation-specific language learning. Journal of Child Language, 10, 551-569.

Snow, C. E., \& Ninio, A. (1986). The contracts of literacy: What children learn from learning to read books. In W. H. Teale \& E. Sulzby (Eds.), Emergent literacy: Reading and writing (pp. 116-138). Norwood, NJ: Ablex.

Storch, S. A., \& Whitehurst, G. J. (2001). The role of family and home in literacy development of children from low-income backgrounds. New Directions for Child and Adolescent Development, 92, 53-71.
Tabors, P. O., Roach, K. A., \& Snow, C. E. (2001). Home language and literacy environment: Final result. In D. A. Dickenson \& P. O. Tabors (Eds.), Beginning literacy with language: Young children learning at home and school (pp. 111-138). Baltimore: Paul H. Brookes.

Taylor, D., \& Dorsey-Gaines, C. (1988). Growing up literate: Learning from inner city families. Portsmouth, NH: Heinemann.

Taylor, D., \& Strickland, D. (1986). Family storybook reading. Portsmouth, NH: Heinemann.

Teale, W. H. (1986). Home background and young children's literacy development. In W. H. Teale \& E. Sulzby (Eds.), Emergent literacy: Writing and reading (pp. 173-206). Norwood, NJ: Ablex.

Whitehurst, G. J., Arnold, D. S., Epstein, J. N., Angell, A. L., Smith, M., \& Fischel, J. (1994). A picture book reading intervention in day care and home for children from low-income families. Developmental Psychology, 30, 679-689.

Woodcock, R. W., \& Johnson, M. B. (1990). Woodcock-Johnson Psychoeducational Battery — revised. Allen, TX: DLM Teaching Resources.

Woodcock, R. W., \& Muñoz-Sandoval, A. F. (2001a). WoodcockMuñoz Language Survey: Normative update, English form. Itasca, IL: Riverside Publishing.

Woodcock, R. W., \& Muñoz-Sandoval, A. F. (2001b). WoodcockMuñoz Language Survey: Normative update, Spanish form. Itasca, IL: Riverside Publishing.

Yarosz, D. J., \& Barnett, W. S. (2001). Who reads to young children? Identifying predictors of family reading activities. Reading Psychology, 22, 67-81.

\section{Appendix}

Tables A1 and A2. 


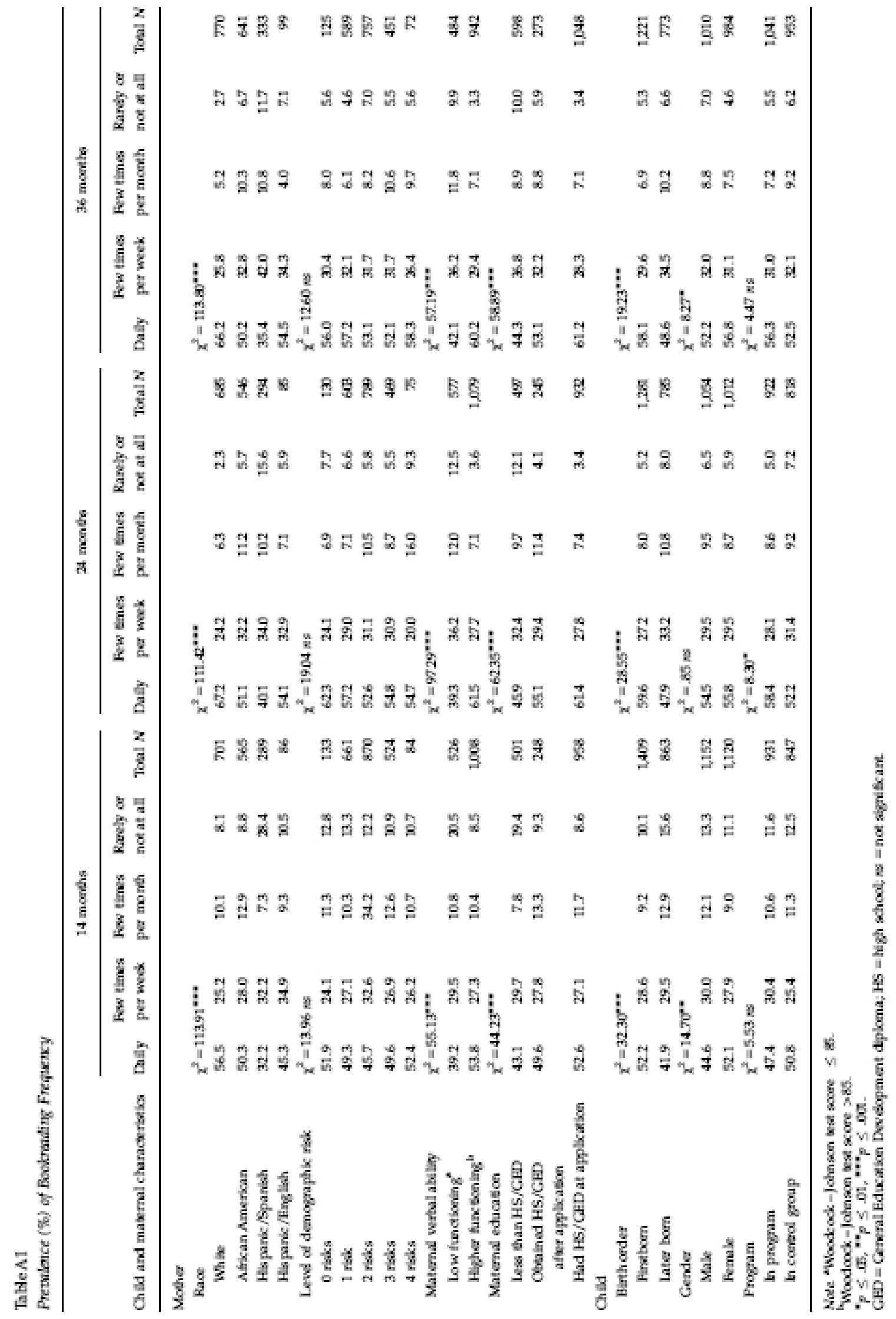


Table A2

Presdace (\%) of Numbar of Childror's Baks in the Home

\begin{tabular}{|c|c|c|c|c|c|c|c|c|c|c|c|c|c|c|c|}
\hline \multirow{2}{*}{$\begin{array}{c}\text { Child and matemal } \\
\text { dharscteristics }\end{array}$} & \multicolumn{5}{|c|}{14 manths } & \multicolumn{5}{|c|}{24 months } & \multicolumn{5}{|c|}{36 months } \\
\hline & 0 & $1-2$ & $3-4$ & $\geq 5$ & Total $N$ & 0 & $1-2$ & $3-4$ & $\geq 5$ & Tokal $N$ & 0 & $1-2$ & $3-9$ & $\geq 10$ & Tokal $N$ \\
\hline \multicolumn{16}{|l|}{ Mother } \\
\hline Race & \multicolumn{5}{|c|}{$x^{2}=198.77^{* * *}$} & \multicolumn{5}{|c|}{$x^{2}=237.89 * * *$} & \multicolumn{5}{|c|}{$x^{2}=183.02^{* * *}$} \\
\hline Whit: & 1.1 & 2.1 & 6.0 & 90.7 & 698 & 0.4 & 06 & 1.7 & 973 & 691 & 0.1 & .6 & 4.9 & 94.4 & 780 \\
\hline African American & 2.1 & 6.4 & 14.0 & 77.6 & 566 & 1.3 & 4.4 & 13.8 & 80.5 & 550 & 0.5 & 2.3 & 18.5 & 78.8 & 655 \\
\hline Hispanic/Spanish & 15.0 & 102 & 16.3 & 58.5 & 294 & 8.1 & 12.5 & 162 & 632 & 296 & 4.7 & 3.3 & 25.4 & 666 & 338 \\
\hline Hisponic/English & 2.4 & 1.2 & 5.9 & 90.6 & 85 & 12 & 3.5 & 4.7 & 90.7 & 86 & 10 & 0 & 60 & 930 & 100 \\
\hline Level of demographic risk & \multicolumn{5}{|c|}{$\chi^{2}=13.06$ ns } & \multicolumn{5}{|c|}{$x^{2}=15.84$ ns } & \multicolumn{5}{|c|}{$x^{2}=13.55 n$} \\
\hline 0 risks & 4.2 & 68 & 5.4 & 83.9 & 118 & 1.7 & 50 & 50 & 882 & 119 & 00 & 0 & 8.8 & 912 & 125 \\
\hline $1 \mathrm{risk}$ & 3.7 & 4.8 & 10.0 & 81.4 & 539 & 2.2 & 52 & 6.5 & 860 & 535 & 1.2 & 2.3 & 123 & 842 & 600 \\
\hline 2 risks & 4.7 & 5.3 & 12.2 & 77.7 & 674 & 2.1 & 4.8 & 9.1 & 839 & 660 & 1.3 & 16 & 13.4 & 83.7 & 766 \\
\hline 3 risks & 3.1 & 5.1 & 11.8 & 80.0 & 390 & 2.1 & 2.1 & 112 & 846 & 383 & 0.9 & 1.3 & 16.7 & 812 & 462 \\
\hline 4 risks & 0.0 & 3.4 & 6.9 & 89.7 & 58 & 3.5 & 1.8 & 76 & 877 & 57 & 1.4 & 1.4 & 12.5 & 84.7 & 72 \\
\hline Maternal verbal ability & \multicolumn{5}{|c|}{$\chi^{2}=147.16^{* * *}$} & \multicolumn{5}{|c|}{$x^{2}=162.52^{* * *}$} & \multicolumn{5}{|c|}{$x^{2}=120.26 * *$} \\
\hline Low functioning & 10.2 & 8.9 & 18.6 & 62.2 & 527 & 5.5 & 96 & 15.1 & 69.7 & 581 & 3.7 & 3.7 & 240 & 686 & 488 \\
\hline Higher functioning & 0.9 & 38 & 8.4 & 87.0 & 1,004 & 0.5 & 16 & 56 & 92.4 & 1,092 & $\infty 0$ & 0.9 & 8.8 & 903 & 957 \\
\hline Maternal education & \multicolumn{5}{|c|}{$x^{2}=73.54^{* * *}$} & \multicolumn{5}{|c|}{$x^{2}=123.85^{* * *}$} & \multicolumn{5}{|c|}{$x^{2}=67.80^{* * *}$} \\
\hline Less than HS/GED & 8.6 & 66 & 14.2 & 70.5 & 499 & 5.8 & 92 & 130 & 720 & 500 & 28 & 2.3 & 19.7 & 752 & 604 \\
\hline Obtained HS/GED & 2.4 & 5.3 & 10.1 & 82.2 & 247 & 00 & 40 & 8.1 & 879 & 248 & 0.4 & 1.1 & 15.1 & 83.5 & 278 \\
\hline after application & & & & & & & & & & & & & & & \\
\hline $\begin{array}{l}\text { Had HS/GED at } \\
\text { application }\end{array}$ & 1.1 & 46 & 8.9 & 85.3 & 962 & 0.7 & 1.6 & 6.1 & 916 & 940 & 0.3 & 1.3 & 9.4 & 890 & 1,067 \\
\hline \multicolumn{16}{|l|}{ Child } \\
\hline Birth order & \multicolumn{5}{|c|}{$x^{2}=17.84^{* * *}$} & \multicolumn{5}{|c|}{$x^{2}=25.50 * \cdots$} & \multicolumn{5}{|c|}{$x^{2}=1953^{* * *}$} \\
\hline Finstbom & 2.4 & 5.3 & 11.0 & 81.4 & 1,101 & 0.9 & 3.4 & 8.9 & 86.7 & 1,073 & 0.4 & 1.1 & 132 & 852 & 1,238 \\
\hline Later bom & 6.3 & 50 & 10.5 & 78.2 & 678 & 4.1 & 56 & 76 & 82.7 & 681 & 22 & 2.4 & 140 & 81.4 & 787 \\
\hline Gender & \multicolumn{5}{|c|}{$\chi^{2}=287 n$} & \multicolumn{5}{|c|}{$x^{2}=4.79 n$} & \multicolumn{5}{|c|}{$x^{2}=1.40 \mathrm{~ns}$} \\
\hline Male & 3.3 & 6.2 & 10.8 & 79.7 & 1,155 & 2.4 & 5.1 & 8.9 & 836 & 1,062 & 1.3 & 1.8 & 140 & 82.9 & 1,025 \\
\hline Female & 4.0 & 4.9 & 11.6 & 79.4 & 1,114 & 1.8 & 35 & 8.3 & 86.4 & 1,023 & 0.9 & 1.5 & 130 & 846 & 999 \\
\hline Program & \multicolumn{5}{|c|}{$x^{2}=40 n s$} & $x^{2}=$ & $987^{*}$ & & & & $x^{2}=$ & 528 & & & \\
\hline In program & 3.5 & 5.7 & 11.4 & 79.4 & 1,158 & 1.3 & 3.7 & 82 & 868 & 1,073 & 1.0 & 1.1 & 126 & 852 & 1,060 \\
\hline In control group & 3.9 & 5.5 & 11.9 & 79.6 & 1,110 & 33 & 5.1 & 8.5 & 832 & 1,010 & 1.1 & 2.2 & 14.5 & 82.2 & 965 \\
\hline
\end{tabular}

Nose 4Woodock- bhrreon test soore $\leq 85$.

b'Wodrack-Jakesion wat soore $>85$.

${ }_{p} \leq 06, \cdots p \leq 01, \cdots p \leq$ D1.

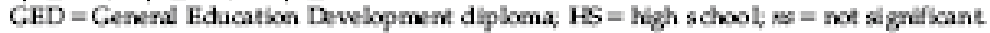

\section{ENDNOTES}

1. The sample was further divided into English speaking ( $n=932)$ and Spanish speaking $(n=169)$ for analyses examining the relation of bookreading to child outcomes, based on whether mothers reported English or Spanish as their primary language. There were differences between the English- and Spanish-speaking groups. Fewer English-speaking mothers were married and living with a husband (26\%) than was true for Spanish-speaking mothers $(47 \%)$. Spanish-speaking mothers were less likely to have finished high school (37\%) than English-speaking mothers $(81 \%)$. The mothers were somewhat similar in the percent who were teens when the focus child was born (40\% for English-speaking vs. 36\% for Spanish-speaking). At 36 months, the
Spanish-speaking sample was defined by the child having a Test de Vocabulario en Imagenes Peabody (TVIP) score, and thus had been designated by the parent as Spanish speaking.

2. We further imputed scores using the sample means for nine cases that were missing baseline data.

3. We further imputed two scores for the 14-month warmth variable, one score for the 24-month warmth variable, and two scores for the 36-month warmth variable. Because baseline data were not available to impute missing values using a regression model, we used the sample means.

4. At 14, 24, and 36 months, across the overall and regression samples, $10-12 \%$ of the interviews with parents were in Spanish; versions of the interviews were translated into Spanish and 
reviewed for local idioms. At 14 and 24 months, 12\% of the MDI assessments were also conducted in Spanish; at 36 months, $14 \%$ were in Spanish. Fewer than $1 \%$ of the interviews and no assessments were conducted in languages other than English or Spanish, using translators.

5. The 1,101 mothers in the regression-only sample read only slightly more frequently than did the mothers in the full readers sample who were not part of the regression sample; thus, $49.5 \%$ (vs. $47.1 \%$ of the no regression study sample) read daily to children at 14 months, and $56.3 \%$ read daily at both 24 and 36 months (vs. 55.4\% and 53.5\%, respectively, for mothers who were not in the regression sample).

6. We also analyzed the likelihood of mothers reading at least several times a week (vs. less often); because results were similar to those for reading daily, they are not reported.

7. We also created interaction terms for race/ethnicity dummy variables by bookreading variables and for program/control by bookreading variables. Of more than 200 interactions across multiple analyses, only four were significant, fewer than would be expected by chance. Nonsignificant interactions suggested that predictions to outcomes for bookreading variables did not vary significantly within these subgroups. Interaction terms were subsequently dropped from the analyses.
8. Because we could not assume that patterns of association found in the path model for the sample of English-speaking dyads would hold true for subgroups, we tested the paths separately for four major race/ethnicity groups: White, Black/ African American, Hispanic English-speaking, and Hispanic Spanish-speaking, as well as for Early Head Start and control groups (tables available upon request). In most cases, reduced sample sizes precluded associations reaching significance levels required for the path model, but we were able to determine whether standardized coefficients were similar in magnitude to those in the full model (or not). Paths for all but one of the subgroups were similar to those found overall. However, the patterns for Spanish-speaking Hispanics were different in some respects from those of other groups. (Spanish-speaking Hispanics were not included in the overall path models.) For Spanish-speaking Hispanics, paths from bookreading at one age to the next and from child language at one age to the next held, but the expected concurrent associations between bookreading and vocabulary at 14 and 24 months and between 14-month vocabulary and 24-month bookreading were not observed. However, similar associations appeared later; relations between vocabulary at 24 months and bookreading at 36 months and between bookreading at 24 and 36 months and outcomes at 36 months were observed.

The findings reported here are based on research conducted as part of the national Early Head Start Research and Evaluation Project funded by the Administration for Children and Families (ACF), U.S. Department of Health and Human Services (DHHS) under contract 105-95-1936 to Mathematica Policy Research Inc., Princeton, NJ, and Columbia University's Center for Children and Families, Teachers College, in conjunction with the Early Head Start Research Consortium. The consortium consists of representatives from 17 programs participating in the evaluation, 15 local research teams, the evaluation contractors, and ACF. Research institutions in the consortium (and principal researchers for conducting this research through 36 months of age) include ACF (Rachel Chazan Cohen, Judith Jerald, Esther Kresh, Helen Raikes, and Louisa Tarullo); Catholic University of America (Michaela Farber, Harriet Liebow, Nancy Taylor, Elizabeth Timberlake, and Shavaun Wall); Columbia University (Lisa Berlin, Christy BradySmith, Jeanne Brooks-Gunn, and Allison Sidle Fuligni); Harvard University (Catherian Ayoub, Barbara Alexander Pan, and Catherine Snow); Iowa State University (Dee Draper, Gayle Luze, Susan McBride, and Carla Peterson); Mathematica Policy Research Inc. (Kimberly Boller, Jill Constantine, Ellen Eliason Kisker, John M. Love, Diane Paulsell, Christine Ross, Peter Schochet, Cheri Vogel, and Welmoet van Kammen); Medical University of South Carolina (Richard Faldowski, Gui-Young Hong, and Susan Pickrel); Michigan State University (Hiram Fitzgerad, Tom Reischl, and Rachel Schiffman); New York University (Mark Spellmann and Catherine Tamis-LeMonda); University of Arkansas (Robert Bradley, Richard Clubb, Andrea Hart, Mark Swanson, and Leanne Witeside-Mansell); University of California, Los Angeles (Carollee Howes and Claire Hamilton); University of Colorado Health Sciences Center (Robert Emde, Jon Korfmacher, JoAnn Robinson, Paul Spicer, and Norman Watt); University of Kansas (Jane Atwater, Judith Carta, and Jean Ann Summers); University of Missouri-Columbia (Mark Fine, Jean Ispa, and Kathy Thornburg); University of Pittsburgh (Beth Green, Carol McAllister, and Robert McCall); University of Washington School of Education (Eduardo Armijo and Joseph Stowitschek); University of Washington School of Nursing (Kathryn Barnard and Susan Spieker); and Utah State University (Lisa Boyce, Gina Cook, Catherine Callow-Heusser, and Lori Roggman). The content of this publication does not necessarily reflect the views or policies of DHHS, nor does mention of trade names, commercial products, or organizations imply endorsement by the U.S. Government. 